\title{
Group 8 Metal Alkynyl Complexes for Nonlinear Optics ${ }^{\dagger}$
}

$5 \quad$ Guillaume Grelaud ${ }^{\mathrm{a}, \mathrm{b}}$, Marie P. Cifuentes ${ }^{\mathrm{a}}$, Frédéric Paul ${ }^{\mathrm{b}}$ and Mark G. Humphrey ${ }^{*, a}$

${ }^{a}$ Research School of Chemistry, Australian National University,

Canberra, ACT 0200, Australia, and ${ }^{b}$ Institut des Sciences Chimiques de Rennes, UMR CNRS 6226,

Université de Rennes 1, Campus de Beaulieu, 35042 Rennes Cedex, France

10

15

${ }^{\dagger}$ Contribution to the $50^{\text {th }}$ Anniversary Special Issue of J. Organomet. Chem.

* Corresponding author. MGH: E-mail: Mark.Humphrey@anu.edu.au. Tel: +61 (0)2 6125 2927. Fax:

$20+61(0) 261250760$. 


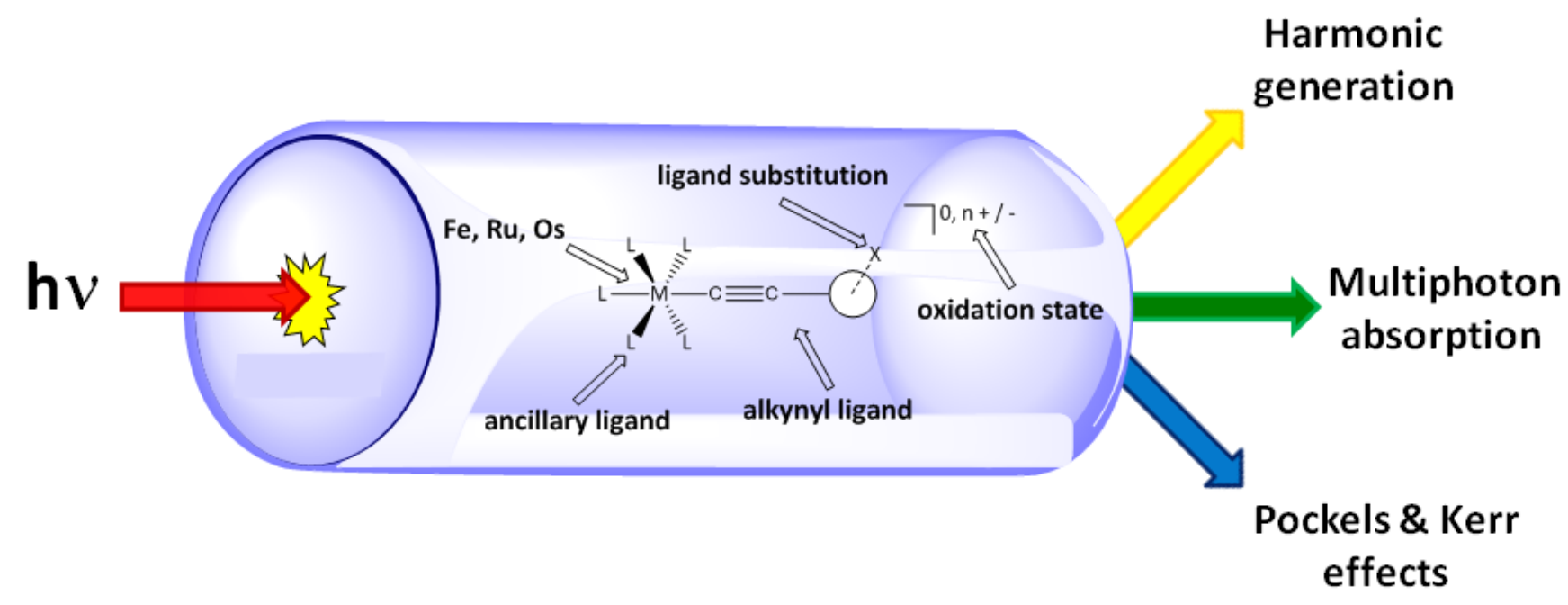




\section{Highlights}

- Group 8 metal alkynyl complexes can be engineered to possess large nonlinearities, which, depending on the specific criteria employed, may be superior to purely organic compounds of similar 5 size

- Dipolar Group 8 metal alkynyl complexes are very efficient as quadratic NLO materials

- Simple quadrupolar and octupolar polynuclear complexes have demonstrable potential with 10 specific cubic NLO properties. Simple tetra- or trinuclear representatives of each are zerogeneration representatives of families of dendrimers, for which nonlinearity increases with generation without loss of transparency

- Switching of NLO properties at the molecular level has been demonstrated with Group 8 metal 15 alkynyl complexes employing multiple orthogonal stimuli (pH, voltage, light) to generate NLOactive (molecular) assemblies that are of interest in logic applications 


\begin{abstract}
Studies of the nonlinear optical (NLO) properties of Group 8 metal alkynyl complexes are summarized, with particular focus on results since 2003; structure-NLO property relationships are developed, optical 5 nonlinearities of multipolar alkynyl complexes are described, and switching of the NLO response of molecules and molecular materials derived from Group 8 metal alkynyl complexes is discussed.
\end{abstract}

Keywords: Acetylide complexes, alkynyl complexes, nonlinear optics, hyperpolarizabilities, quadratic 10 nonlinearities, cubic nonlinearities. 


\section{Contents}

1. Introduction

2. NLO theory and experimental techniques

5 2.1. NLO phenomena

2.2. Experimental techniques

3. Quadratic NLO studies

3.1. General comments

3.2. Modulation of the ligated metal donor strength

10 3.3. $\pi$-Bridge optimization

3.4. Octupolar complexes

4. Cubic NLO studies

4.1. General comments

4.2. Dipolar complexes

15 4.3. Quadrupolar complexes

4.4. Octupolar complexes

5. Switching NLO properties

5.1. General comments

5.2. Switching of quadratic NLO properties

$20 \quad$ 5.3. Switching of cubic NLO properties

5.4. Towards switchable molecule-based materials with metal alkynyl complexes?

5.4.1. Materials for switching of quadratic NLO properties

5.4.1. Materials for switching of cubic NLO properties

6. Conclusion 
Acknowledgements

\section{References}




\section{Introduction}

When light interacts with materials possessing nonlinear optical (NLO) properties, the incident light can be modified (e.g. the phase, frequency, amplitude, polarization, path, etc..., of the incident light can all 5 be changed); as a consequence, NLO materials have many possible applications (e.g. optical signal processing, switching, frequency generation, optical data storage, optical communication, and image processing). Due to these possible applications, there has been strong interest in the NLO properties of organometallic and/or coordination complexes over the past decade [1-9], amongst which metallocenyl and metal alkynyl complexes have commanded significant attention. We previously comprehensively 10 surveyed the NLO properties of metal alkynyl complexes through 2002 [1], at which time studies of the quadratic and cubic nonlinearities of complexes had been undertaken at specific wavelengths to tentatively establish structure-NLO property relationships. Since then, several advances have been reported: access to tuneable laser systems has enabled complete spectral dependence studies of nonlinearities, permitting the maximal values of the quadratic and cubic NLO coefficients to be obtained

15 and structure-property relationships to be improved; the possibility of complexes functioning as NLO switches has been assessed; and the dipolar composition of complexes in the earlier studies has been expanded to embrace a variety of multipolar charge distributions, especially those that are quadrupolar or octupolar in nature. Previous reviews have contained comprehensive discussions of the theory behind nonlinear optics and experimental procedures to measure NLO effects - this material will not be 20 reproduced in detail here (although a brief summary of the theory has been provided to clarify the subsequent discussion) - rather, the present account focuses on the NLO properties of Group 8 metal alkynyl complexes, with an emphasis on results reported since 2003, and with a focus on illustrating the new trends such as switching of the NLO properties, as well as the challenges associated with shifting from molecule-based switching (most often performed in solution) to switchable (bulk) materials or 
interfaces. A more comprehensive discussion of NLO-switching using metal alkynyl complexes in solution can be found in a review recently published by some of us [9].

\section{NLO theory and experimental techniques}

5

\subsection{NLO phenomena}

Nonlinear optical phenomena arise from the interaction of matter with strong electromagnetic fields. For organic and organometallic molecules it is convenient to consider such interactions at a molecular level. 10 When a light beam, via its associated electric field $\mathbf{E}$, interacts with the polarizable electrons of a molecule, it generates a distortion in the electron density distribution $\rho(r)$, resulting in an induced dipole moment $\boldsymbol{\mu}$. The dipole moment (or polarization on a macroscopic scale) varies in a linear relationship to the magnitude of a relatively weak field. However, if the electric field $\mathbf{E}$ is strong (such as with lasers) and is comparable in strength to the internal electric fields within the molecule, the linear relationship is 15 no longer valid. The induced dipole moment is no longer linearly proportional to the intensity of the electric field, but instead involves quadratic, cubic, etc, terms that are dependent on $\mathbf{E}$. This dependence of the dipole moment on the electric field can be represented as a power series (equation 1):

$$
\boldsymbol{\mu}=\boldsymbol{\mu}_{0}+\alpha \mathbf{E}+\beta \mathbf{E} \mathbf{E}+\gamma \mathbf{E} \mathbf{E} \mathbf{E}+\ldots
$$

where $\boldsymbol{\mu}_{0}$ is the static dipole moment, $\alpha$ is the linear polarizability, $\beta$ is the molecular first 20 hyperpolarizability and $\gamma$ is the molecular second hyperpolarizability. As $\boldsymbol{\mu}$ and $\mathbf{E}$ are vectors, the polarizabilities are tensors of the appropriate ranks: $\alpha \square$ s a second-rank tensor, $\beta$ is a third-rank tensor, and $\gamma$ is a fourth-rank tensor. The quadratic coefficient $\beta$ is associated with second-order NLO 
phenomena, whereas third-order phenomena are related to terms in which the cubic coefficient $\gamma$ appears. One can readily see the implications of this - the electric field of a light wave can be expressed as:

$$
\mathbf{E}(\mathrm{t})=\mathbf{E}_{0} \cos (\omega \mathrm{t})
$$

and after substituting equation 2 into equation 1, truncating at the cubic term, and expanding using 5 trigonometric relations, one obtains:

$$
\boldsymbol{\mu}=\boldsymbol{\mu}_{0}+\alpha \mathbf{E}_{0} \cos (\omega \mathrm{t})+\frac{1}{2} \beta \mathbf{E}_{0}^{2}+\frac{1}{2} \beta \mathbf{E}_{0}^{2} \cos (2 \omega t)+\frac{3}{8} \gamma \mathbf{E}_{0}^{3} \cos (\omega t)+\frac{1}{8} \gamma \mathbf{E}_{0}^{3} \cos (3 \omega t)
$$

Thus, the nonlinear terms in the dipole moment expansion introduce contributions at frequencies $2 \omega$ and $3 \omega$, corresponding to frequency doubling and tripling. The values of the tensors $\beta$ and $\gamma$ are usually 10 expressed in electrostatic units (esu), and are strongly dependent on the frequency of the incident laser beam. The coefficients $\beta$ and $\gamma$ are complex, with real and imaginary parts: for second-order NLO effects, only the real part is important, but for third-order NLO performance, both real and imaginary parts have to be taken into account.

15 The three major technological applications of second-order NLO effects thus far involve the modulation of the phase, frequency and path of light beams. The Pockels or linear electro-optic effect ( $\boldsymbol{\mu}=\boldsymbol{\mu}_{0}+$ $1 / 2 \beta \mathbf{E}_{0}^{2}$ in equation 3 ) is the modification of the refractive index of an optical medium when exposed to a static (or varying) electric field. The birefringence produced in the medium is directly proportional to the electric field. The applications of the effect are the modulation of the amplitude, phase and path of a 20 light beam, usually to enable it to carry binary information. Sum frequency generation (SFG) is a process in which two signals at frequencies $\omega_{1}$ and $\omega_{2}$ are summed to give a signal at frequency $\omega_{3}\left(\omega_{1}+\omega_{2} \rightarrow\right.$ $\omega_{3}$ ). The opposite effect also exists, called difference frequency generation (DFG): the output signal at frequency $\omega_{3}$ is the difference of the frequencies of the two input signals $\left(\omega_{1}-\omega_{2} \rightarrow \omega_{3}\right.$, assuming $\omega_{1}>$ 
$\left.\omega_{2}\right)$. A special case of SFG, and also the most common, is second-harmonic generation (SHG): two input signals of the same frequency $\left(\omega_{1}=\omega_{2}=\omega\right)$ result in an output signal of double the frequency $(\omega+\omega \rightarrow$

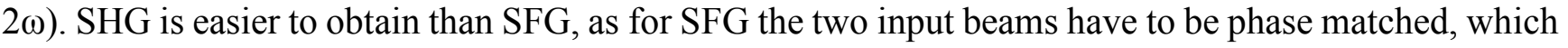
is more difficult to realize experimentally. SHG has been mostly used for the conversion of infrared 5 radiation into visible light or visible into ultraviolet light. The efficiency of this process is highly dependent on $\beta$ (equation 3), and for a given material, on the frequency of the laser $\omega$. Parametric generation, in which a signal at frequency $\omega_{1}$ is split into two signals at frequencies $\omega_{2}$ and $\omega_{3}\left(\omega_{1} \rightarrow \omega_{2}\right.$ $\left.+\omega_{3}\right)$, can be considered as the reverse phenomenon of SFG. This process is widely used for the generation of infrared laser beams from visible or near-infrared beams.

Third-order NLO effects are numerous and, as is the case with their second-order counterparts, they depend on the frequency of the incident light beam. At a given wavelength, third-order NLO properties are related to the cubic coefficient $\gamma$. As indicated above, $\gamma$ is a complex number and can be divided into its real and imaginary parts (equation 4):

$$
\gamma=\sqrt{\gamma_{\text {real }}^{2}+\gamma_{\text {imag }}^{2}}
$$

The real part is responsible for the modifications of the refractive properties of the molecule while the modifications of the absorptive properties are related to the imaginary part of $\gamma$. The refractive part includes instantaneous electronic effects such as the quadratic electro-optic effect (Kerr effect) or frequency tripling, and the imaginary part is responsible for absorptive phenomena (multi-photon 20 absorption, saturable absorption). As these phenomena have different response times, time-resolved measurements have to be undertaken to determine which mechanisms are involved in the third-order NLO response of a given molecule or material. Many third-order NLO processes exist, some constituting valuable tools for nonlinear spectroscopy, while others have a greater technological importance. The presence of $\gamma$ in any substance means that all materials are susceptible to third-harmonic generation. The 
frequency tripling of a light beam by the direct process of third-harmonic generation is, however, not practically exploited, a cascade of two consecutive second-order mixing processes being preferred for the generation of short wavelength laser beams $(\omega+\omega \rightarrow 2 \omega$ and $2 \omega+\omega \rightarrow 3 \omega)$; one reason for this is that phase matching is virtually impossible to achieve for third-harmonic generation. Of greater 5 technological importance are all-optical processes, such as the Kerr effect and two-photon absorption. The Kerr effect is based on the same principle as the Pockels effect and is its third-order equivalent. In the Kerr effect (or quadratic electro-optic effect), the modification of the refractive index of the medium varies as a function of the square of the applied electric field, instead of varying linearly with the electric field as in the Pockels effect. The main interest with the Kerr effect, as with the Pockels effect, is to 10 instantaneously modify the path of the light beam through a material (e.g. to encode information onto a light beam). Two-photon absorption (2PA) corresponds to the simultaneous absorption of two photons by a compound. In the degenerate case, the two photons absorbed are of the same energy, whereas in the non-degenerate case their energies are different. A sufficient density of photons is needed for such simultaneous absorption, necessitating the use of lasers. In the absence of any one-photon absorption, 15 the transmission $\mathrm{T}$ of a light beam through a two-photon absorbing material is given by equation $\mathbf{5}$ :

$$
T=\frac{I}{I_{0}}=\frac{1}{1+I_{0} \beta_{2} L}
$$

When the intensity $I_{0}$ of the light beam increases, the transmitted intensity I tends to saturate at $\left(\beta_{2} L\right)^{-1}$ (with $L$ the length of the sample), corresponding to the optical limiting power. $\beta_{2}$ is proportional to the $202 \mathrm{PA}$ cross-section $\sigma_{2}$ and the concentration of active compound in the sample. The 2PA cross-section is conveniently expressed in Goeppert-Mayer units $\left(1 \mathrm{GM}=10^{-50} \mathrm{~cm}^{4}\right.$ photon $^{-1}$ molecule $\left.^{-1}\right)$. In principle, the direct process of two-photon absorption is suitable for optical limiting (attenuation of high power beams occurs because their high photon density permits 2PA). In practice, the power limiting properties of existing materials, even those with the largest two-photon absorption coefficients, are still insufficient 
for the efficient protection of sensors from laser pulses of nanosecond duration. Saturable absorption (SA) and reverse saturable absorption (RSA) are, similar to 2PA, absorptive phenomena related to the imaginary part of $\gamma$ in which two photons are absorbed. The difference with 2PA is temporal; the two photons are absorbed one after another in SA and RSA, in contrast to 2PA in which the process is

5 simultaneous. Due to this stepwise nature, a real excited state of the molecule is involved from which the second photon is then absorbed in a process called excited-state absorption (ESA). If a substantial proportion of molecules are in this excited state, the transmission properties of the medium are no longer the same: the excited state has different absorptive properties from the ground state. For RSA, a "photodarkening" effect is observed: the transmission of the medium is decreased as the compound in

10 this excited state has greater absorptivity than in the ground state at a given wavelength. In contrast, if the excited state has a lower absorptivity than the ground state, the transmission of the sample will be increased as ground-state molecules are depleted: an absorption bleaching will be observed (saturable absorption). In other words, if the absorption cross-section of the medium in the excited state is lower than in the ground state, the transmission of the system increases once the medium is excited. It should 15 be noted that when $\gamma_{\text {imag }}>0$, the compound acts as a two-photon absorber, whereas when $\gamma_{\text {imag }}<0$, the compound has saturable absorber properties.

\subsection{Experimental techniques}

20 A large number of techniques have been used to measure the second- and third-order NLO responses of molecules, those used to examine Group 8 metal alkynyl complexes including the Kurtz powder technique, electric field-induced second-harmonic generation (EFISH), hyper-Rayleigh scattering (HRS), degenerate four-wave mixing (DFWM), and Z-scan; detailed descriptions of these can be found 
elsewhere, together with a discussion of the difficulties in comparing data obtained with different techniques in different laboratories [4]. In the past 10 years, the focus of studies of the NLO properties of Group 8 metal alkynyl complexes has increasingly shifted to HRS (usually using ns pulses) and Zscan (mainly using fs pulses), due to their widespread applicability and comparative simplicity. Optical

5 nonlinearities are wavelength dependent, but over the past decade, tuneable light sources have become available, which has permitted maximal values of cubic nonlinearities to be obtained and structure-cubic NLO property relationships to be developed for metal alkynyl complexes. The following sections summarize quadratic and cubic NLO results for Group 8 metal alkynyl complexes since 2003.

\section{3. Quadratic NLO studies}

\subsection{General comments}

Both dipolar and octupolar molecules can possess significant quadratic NLO properties. Very early in 15 the search for NLO materials, it was recognized that molecules consisting of donor and acceptor groups linked with an unsaturated bridge possessing polarizable $\pi$-electrons were particularly NLO-efficient. A two-level model involving the ground state and the first excited state of a compound was used to explain these observations [10], and to afford design rules for efficient second-order NLO molecules; such molecules must (i) be non-centrosymmetric ( $\beta=0$ for centrosymmetric compounds), (ii) have a low 20 energy for the ground state to first excited-state transition, and (iii) have a strong intramolecular charge transfer for this lowest energy transition. For a given unsaturated linker, an optimum combination of donor and acceptor groups exists to maximize the $\beta$ coefficient $[11,12]$. 
In the early 1990s, it was noted that octupolar molecules, when possessing a specific symmetry $\left(D_{3}, D_{3 h}\right.$, $\left.T_{d}, D_{2 d} \ldots\right)$, can have large nonlinearities despite their lack of a net dipole moment [13]. As is the case with dipolar compounds, the strength of the donor and the acceptor groups, as well as the nature of the unsaturated bridging unit, play an important role in the magnitude of the quadratic NLO coefficient. The

5 global $\beta$ value can therefore be deconvoluted into two components, corresponding to dipolar and octupolar contributions. In octupolar compounds, the dipolar contribution is zero and only the octupolar contribution is active, whereas in dipolar compounds, the octupolar contribution is usually weak and can be neglected. Since 2003, dipolar metal alkynyl complexes have continued to command interest as quadratic NLO materials, but octupolar complexes have also attracted interest. As discussed below, the 10 major contributions to these developments with dipolar Group 8 metal alkynyl complexes in this period have been in optimizing the $\pi$-bridge (by chain lengthening and compositional modification) and in the modulation of the ligated metal donor strength (by reversible oxidation), whereas the focus with octupolar Group 8 metal alkynyl complexes has been zero- and first-generation dendrimers.

\section{3.2. Modulation of the ligated metal donor strength}

One possibility for tuning the quadratic NLO properties of organometallics that was explored in the 1990s was the modification of the donor strength of the metal [1], usually via ligand replacement at the metal center, and this is an approach to varying $\beta$ that continues to attract interest. Replacement of 20 electron-withdrawing carbonyl ligands with phosphine ligands or cyclopentadienyl ligands by pentaphenylcyclopentadienyl ligands (Figure 1) increases the donor strength of the ligated ruthenium in 4-nitrophenylalkynyl complexes, with a concomitant increase in $\beta$ value (Table 1) [14]. Varying the metal center has also been investigated. While complexes of group 8 metals are highly active [1,4], 
comparison of identically ligated iron and ruthenium complexes revealed different trends, depending on the specific complexes (cf. refs [14-16] with $[17,18]$ ). In contrast, results thus far suggest that, for a given ligand sphere, osmium outperforms iron and ruthenium [1].

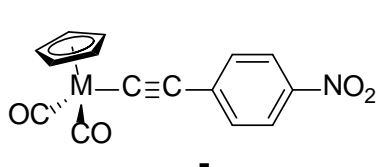

$1 a^{\top} \mathrm{b}$

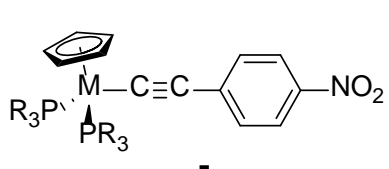

$2^{a} \mathrm{c}$

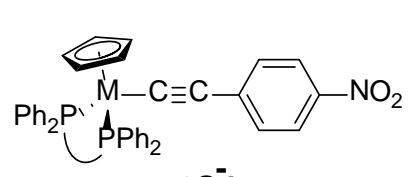

$3^{a} \mathrm{~b}$

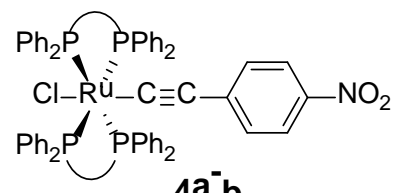

$4 a^{-} b$

5 Figure 1. Selected 4-nitrophenylalkynyl complexes (see Table 1 for specific composition).

\begin{tabular}{ccccc}
\hline$[\mathrm{Ru}]-\mathrm{C} \equiv \mathrm{C}-\mathrm{NO}_{2} ;[\mathrm{Ru}]=$ & $\mathbf{C o m p l e x}$ & $\begin{array}{c}\boldsymbol{\beta} \\
\left(10^{-30} \mathrm{esu}\right)\end{array}$ & $\begin{array}{c}\boldsymbol{\beta}_{\mathbf{0}} \\
\left(10^{-30} \mathrm{esu}\right)\end{array}$ & $\begin{array}{c}\lambda_{\max }[\boldsymbol{\varepsilon}] \\
\left(\mathrm{nm},\left[10^{4} \mathrm{M}^{-1} \mathrm{~cm}^{-1}\right]\right)\end{array}$ \\
\hline$\left(\eta^{5}-\mathrm{C}_{5} \mathrm{H}_{5}\right)(\mathrm{CO})_{2} \mathrm{Ru}$ & $\mathbf{1 a}$ & 58 & 27 & $364[1.6]$ \\
$\left(\eta^{5}-\mathrm{C}_{5} \mathrm{H}_{5}\right)(\mathrm{CO})_{2} \mathrm{Fe}$ & $\mathbf{1 b}$ & 49 & 22 & $370[1.3]$ \\
$\left(\eta^{5}-\mathrm{C}_{5} \mathrm{H}_{5}\right)\left(\mathrm{PPh}_{3}\right)_{2} \mathrm{Ru}$ & $\mathbf{2 a}$ & 468 & 96 & $460[1.1]$ \\
$\left(\eta^{5}-\mathrm{C}_{5} \mathrm{H}_{5}\right)\left(\mathrm{PPh}_{3}\right)_{2} \mathrm{Os}$ & $\mathbf{2 b}$ & 1051 & 174 & $474[2.2]$ \\
$\left(\eta^{5}-\mathrm{C}_{5} \mathrm{H}_{5}\right)\left(\mathrm{PMe}_{3}\right)_{2} \mathrm{Ru}$ & $\mathbf{2 c}$ & 248 & 38 & $477[4.0]$ \\
$\left(\eta^{5}-\mathrm{C}_{5} \mathrm{H}_{5}\right)\left(\kappa^{2}-\mathrm{dppe}\right) \mathrm{Ru}$ & $\mathbf{3 a}$ & 664 & 161 & $447[1.8]$ \\
$\left(\eta^{5}-\mathrm{C}_{5} \mathrm{H}_{5}\right)\left(\kappa^{2}-\mathrm{dppf}\right) \mathrm{Ru}$ & $\mathbf{3 b}$ & 770 & 165 & $469[1.7]$ \\
$\mathrm{Cl}\left(\kappa^{2}-\mathrm{dppe}\right)_{2} \mathrm{Ru}$ & $\mathbf{4 a}$ & $562 \pm 9$ & $88 \pm 1$ & $477[2.0]$ \\
$\mathrm{Cl}\left(\kappa^{2}-\mathrm{dppm}\right)_{2} \mathrm{Ru}$ & $\mathbf{4 b}$ & 767 & 129 & $473[1.8]$
\end{tabular}

Table 1. Second-order NLO responses determined by HRS at $1064 \mathrm{~nm}$ for the 4-nitrophenylalkynyl complexes represented in Figure $1[1,9,14,19-21] . \beta$ values are $\pm 10 \%$ unless otherwise specified and are corrected for resonance enhancement at $532 \mathrm{~nm}$ using the two-level model with $\beta_{0}=\beta[1-$ $\left.10\left(2 \lambda_{\max } / 1064\right)^{2}\right]\left[1-\left(\lambda_{\max } / 1064\right)^{2}\right]$.

Group 8 metal alkynyl complexes often possess a reversible redox process $\left(\mathrm{M}^{\mathrm{II}} / \mathrm{M}^{\mathrm{III}}\right)$, permitting the interconversion of the complexes between the two oxidation states. If the two redox states have different nonlinear optical properties, this affords a "redox switching" of the NLO response. While the " $\mathrm{M}^{\mathrm{II}} / \mathrm{M}^{\mathrm{III}}$ " 15 notation is rather formal, because the electronic vacancy can be more or less delocalized over the alkynyl 
bridge depending on the nature of the metal center $(\mathrm{Ru}>\mathrm{Fe})$ [22], it is broadly correct for arylalkynyl complexes in the sense that the largest positive charge per atom is located at the metal center, regardless of the metal in the $\mathrm{Fe} / \mathrm{Ru} / \mathrm{Os}$ series. A decrease in the NLO response is thus intuitively expected on proceeding to the oxidized complexes due to the decrease of the electron-releasing character of the metal

5 center in the corresponding cation, and this is usually observed [9,17]. However, in principle, depending on the magnitude of the "umpolung" taking place, the change in NLO response between the two redox states can involve quenching of the NLO activity, or even increasing the absolute magnitude of the response.

10 The replacement of dppe by a redox-active ligand such as 1,1'-bis(diphenylphosphino)ferrocene (dppf) is another potential approach to tune the NLO activity using oxidized states. This compositional modification has been recently investigated in 4-nitrophenylalkynyl ruthenium complexes 3 (Figure 1). Although little measurable difference in $\beta$ value results when progressing from $\mathbf{3 a}$ to $\mathbf{3 b}$ (Figure 1), introduction of such a redox-active diphosphine does impart potentially useful additional functionality $15[21]$.

\section{3. $\pi$-Bridge optimization}

Another possibility for increasing the magnitude of the NLO response of alkynyl complexes is to 20 lengthen the $\pi$-conjugated alkynyl ligand, e.g. by increasing the number of "-C $\equiv \mathrm{C}-4-\mathrm{C}_{6} \mathrm{H}_{4}$-" units in acceptor-functionalized oligo(phenyleneethynylene) (OPE)-type ligands. Earlier studies with alkynyl complexes had revealed that increasing the $\pi$-bridge length of the alkynyl ligand results in an enhancement in both the $\beta$ and $\gamma$ values [1,18,23-27]. For example, when proceeding from 4$\mathrm{C} \equiv \mathrm{CC}_{6} \mathrm{H}_{4} \mathrm{NO}_{2}$ complexes to $4-\mathrm{C} \equiv \mathrm{CC}_{6} \mathrm{H}_{4} \mathrm{C} \equiv \mathrm{C}-4-\mathrm{C}_{6} \mathrm{H}_{4} \mathrm{NO}_{2}$ complexes, by formal insertion of a 
phenyleneethynylene unit, the $\beta$ value of the resultant complexes is on average double that of the shorter homologue, while $\gamma_{\text {imag }}$ is increased significantly (up to $c a$. thirty-fold) [28].

It was observed in earlier studies with organic molecules that nonlinearities saturate as the $\pi$-bridge 5 length is increased, and this saturation length has now been assessed for ruthenium alkynyl complexes. For two series of complexes 4-11 (Figure 2, Table 2), differing in their bidentate diphosphine ligand [bis(diphenylphosphino)methane (dppm) vs. 1,2-bis(diphenylphosphino)ethane (dppe)], the effect of $\pi$ bridge lengthening between the metal center and the terminal 4-nitrophenyl group is clearly evident: increasing the length of the alkynyl ligand by formal sequential insertion of two phenyleneethynylene 10 units results in an increase in both $\beta$ and $\beta_{0}$ values [19,28]. Ethoxy groups were introduced at the 2- and 5-positions of one or more of the OPE ring(s) to ensure sufficient solubility of the complexes to measure NLO activity (Figure 2). The introduction of the ethoxy groups on the ligand results in a reduction of 30 $\%$ of the magnitude of the second-order NLO response, but with four ethoxy groups ( $\left.n^{\prime} \geq 2\right)$, no further change was noted (within the error margins). From the results (Table 2), a saturation effect is evident: 15 the $\beta$ value increases on proceeding from the simple 4-nitrophenylalkynyl complex $\mathbf{4 b}$ to $\mathbf{7}$ (after factoring in a $30 \%$ decrease of the value of the former for the presence of two ethoxy groups), but decreases on $\pi$-lengthening the tri(phenyleneethynylene) complex (from 8 to 9 and 10). The same saturation behaviour was observed with organoiron $\mathrm{Fe}\left(\kappa^{2}\right.$-dppe $)\left(\eta^{5}-\mathrm{C}_{5} \mathrm{Me}_{5}\right)$ analogues; in this case, however, saturation was reached with the complex possessing two phenyleneethynylene units in the $\pi$ 20 bridge [29]. The origin of the saturation effect upon lengthening of the alkynyl ligand remains unexplained, but can possibly be linked to the breakdown of the donor-acceptor interaction once a critical length of the alkynyl ligand is reached. 


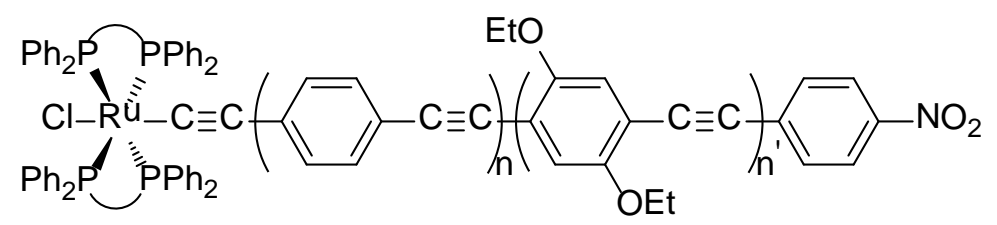

Figure 2. Complexes 4 - 11.

\begin{tabular}{ccccc}
\hline Complex & $\mathbf{n}$ & $\mathbf{n}^{\prime}$ & $\begin{array}{c}\boldsymbol{\beta} \\
\left(10^{-30} \text { esu }\right)\end{array}$ & $\begin{array}{c}\boldsymbol{\beta}_{0} \\
\left(10^{-30} \mathrm{esu}\right)\end{array}$ \\
\hline $\mathbf{4 a}$ & 0 & 0 & dppe complexes & \\
$\mathbf{5 a}$ & 1 & 0 & $562 \pm 9$ & $88 \pm 1$ \\
$\mathbf{6 a}$ & 2 & 0 & $1240 \pm 110$ & $225 \pm 20$ \\
\hline & & & dppm complexes & $388 \pm 32$ \\
\hline $\mathbf{4 b}$ & 0 & 0 & 767 & 129 \\
$\mathbf{5 b}$ & 1 & 0 & 833 & 161 \\
$\mathbf{6 b}$ & 2 & 0 & 1379 & 365 \\
$\mathbf{7}$ & 0 & 1 & $570 \pm 90$ & $40 \pm 6$ \\
$\mathbf{8}$ & 1 & 1 & $916 \pm 153$ & $208 \pm 42$ \\
$\mathbf{9}$ & 1 & 2 & $678 \pm 139$ & $217 \pm 35$ \\
$\mathbf{1 0}$ & 2 & 1 & $632 \pm 103$ & $185 \pm 10$ \\
$\mathbf{1 1}$ & 2 & 2 & $580 \pm 20$ & \\
\hline
\end{tabular}

Table 2. Second-order NLO responses determined by HRS at $1064 \mathrm{~nm}$ for $\mathbf{4 a - 6 a}$ and $\mathbf{4 b} \mathbf{b} \mathbf{6} \mathbf{b}, \mathbf{7}-\mathbf{1 1}$, 5 illustrating saturation of quadratic nonlinearity on $\pi$-bridge lengthening $[19,28]$. $\beta$ values are $\pm 10 \%$ unless otherwise specified and are corrected for resonance enhancement at $532 \mathrm{~nm}$ using the two-level model with $\beta_{0}=\beta\left[1-\left(2 \lambda_{\max } / 1064\right)^{2}\right]\left[1-\left(\lambda_{\max } / 1064\right)^{2}\right]$. 


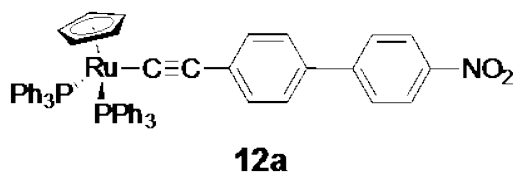

12a

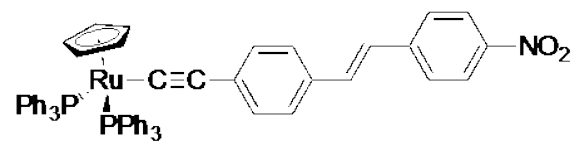

$12 b$

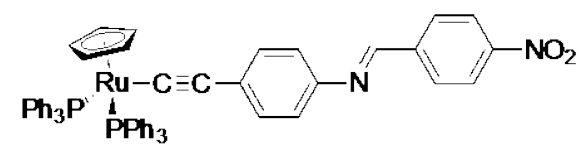

12c

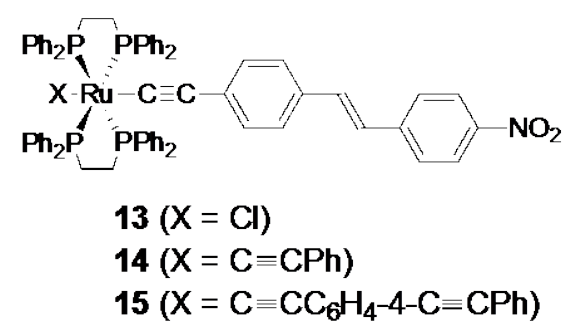

Figure 3. Complexes 12a-c, 13-15.

Further bridge modification has been examined in the past decade. Earlier studies with azo-linked 5 analogues [24] of alkynyl complexes such as 12a-c (Figure 3) [20,30] have been extended to examples with longer $\pi$-bridges [31], with both azo for $E$-ene replacement and bridge lengthening significantly increasing quadratic nonlinearity. $\pi$-Bridge lengthening at the coordination site trans to the nitro-

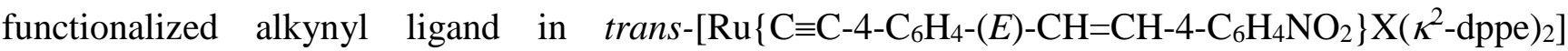
complexes, proceeding from $\mathrm{X}=\mathrm{Cl}(\mathbf{1 3})$ to $\mathrm{C} \equiv \mathrm{CPh}(\mathbf{1 4})$ and then $\mathrm{C} \equiv \mathrm{C}-4-\mathrm{C}_{6} \mathrm{H}_{4} \mathrm{C} \equiv \mathrm{CPh}(\mathbf{1 5})$ resulted in 10 further increases in $\beta$ and $\beta_{0}$ and afforded organometallic complexes with amongst the largest quadratic nonlinearities thus far [32].
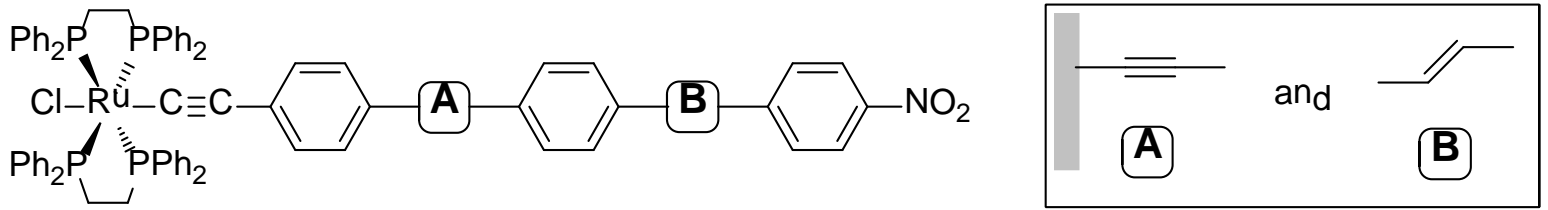

Figure 4. Complexes 16 - 19.

15

The effect of replacing one or two ethynyl linkages by alkenyl groups in tri(phenyleneethynylene)-linked complexes (Figure 4) has been assessed [33], the results being summarized in Table 3. The replacement 
of the yne adjacent to the metal-bound phenylethynyl unit (the "A" linkage) by an $E$-ene linkage leads to a significant increase in the $\beta$ value at both wavelengths studied. In contrast, replacement of the yne unit by an $E$-ene linking unit at the "B" linkage, more remote from the metal center, results in a much less significant increase in the second-order NLO response. For complexes with two $E$-alkenyl linkages, 5 the $\beta$ values fall between the values of complexes incorporating only one $E$-alkenyl linkage (i.e. at one of the two possible sites).

\begin{tabular}{ccccccc}
\hline & & & \multicolumn{2}{c}{ HRS, $1064 \mathrm{~nm}$} & \multicolumn{2}{c}{ HRS, $1300 \mathrm{~nm}$} \\
\cline { 4 - 7 } & \multirow{2}{nnyyyy}{} & B & $\begin{array}{c}\boldsymbol{\beta} \\
\left(10^{-30} \mathrm{esu}\right)\end{array}$ & $\begin{array}{c}\boldsymbol{\beta}_{\mathbf{0}} \\
\left(10^{-30} \mathrm{esu}\right)\end{array}$ & $\begin{array}{c}\boldsymbol{\beta} \\
\left(10^{-30} \mathrm{esu}\right)\end{array}$ & $\begin{array}{c}\boldsymbol{\beta}_{\mathbf{0}} \\
\left(10^{-30} \mathrm{esu}\right)\end{array}$ \\
\hline $\mathbf{1 6}$ & -yne & -yne & $1327 \pm 110$ & $388 \pm 32$ & $42 \pm 2$ & $21 \pm 1$ \\
$\mathbf{1 7}$ & -ene & -yne & $2800 \pm 280$ & 580 & 90 & 40 \\
$\mathbf{1 8}$ & -yne & -ene & $1800 \pm 180$ & 430 & 80 & 38 \\
$\mathbf{1 9}$ & -ene & -ene & $2525 \pm 175$ & $460 \pm 32$ & $80 \pm 4$ & $34 \pm 2$ \\
\hline
\end{tabular}

Table 3. Second-order NLO responses of complexes $\mathbf{1 6}-\mathbf{1 9}$ by HRS at 1064 or $1300 \mathrm{~nm}$ [33]. $\beta$ values are $\pm 10 \%$ unless otherwise specified and are corrected for resonance enhancement at $532 \mathrm{~nm}$ using the 10 two-level model with $\beta_{0}=\beta\left[1-\left(2 \lambda_{\max } / 1064\right)^{2}\right]\left[1-\left(\lambda_{\max } / 1064\right)^{2}\right]$.

\subsection{Octupolar complexes}

15 As was mentioned above, the search for new molecular materials with enhanced NLO coefficients has resulted in a progression from the extensively-studied donor-bridge-acceptor dipolar composition to alternative molecular geometries. There has been considerable interest in the cubic NLO properties of metal alkynyl complexes with higher multi-polar charge distributions in the past decade (quadrupolar, 
octupolar: see sections 4.3. and 4.4.), but there have been significantly fewer reports of the quadratic nonlinearities of octupolar Group 8 metal alkynyl complexes, a rare example being the molecular first hyperpolarizabilities of the formally octupolar zero- and first-generation dendrimers in Figure 5, assessed by HRS at $1064 \mathrm{~nm}$ (Table 4) [34]. The NLO properties of metal alkynyl dendrimers have 5 recently been reviewed [35].

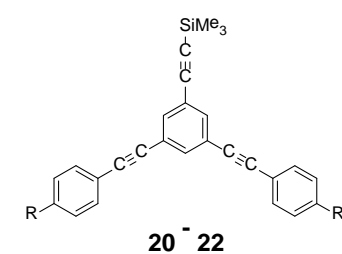

$20^{-} 22$

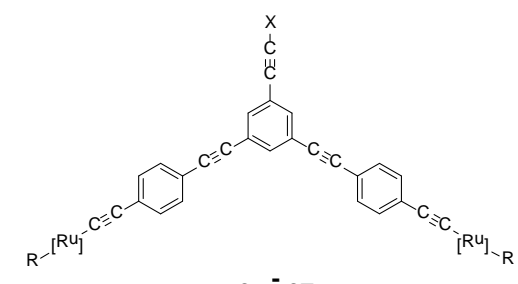

$23^{-} 27$

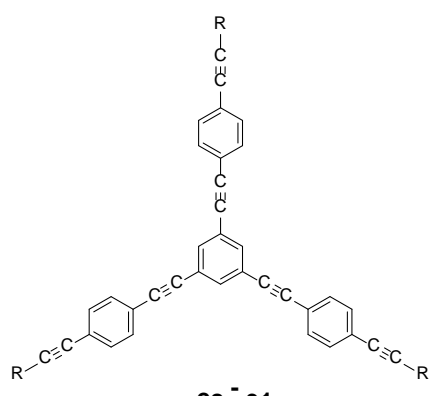

$28^{-} 31$

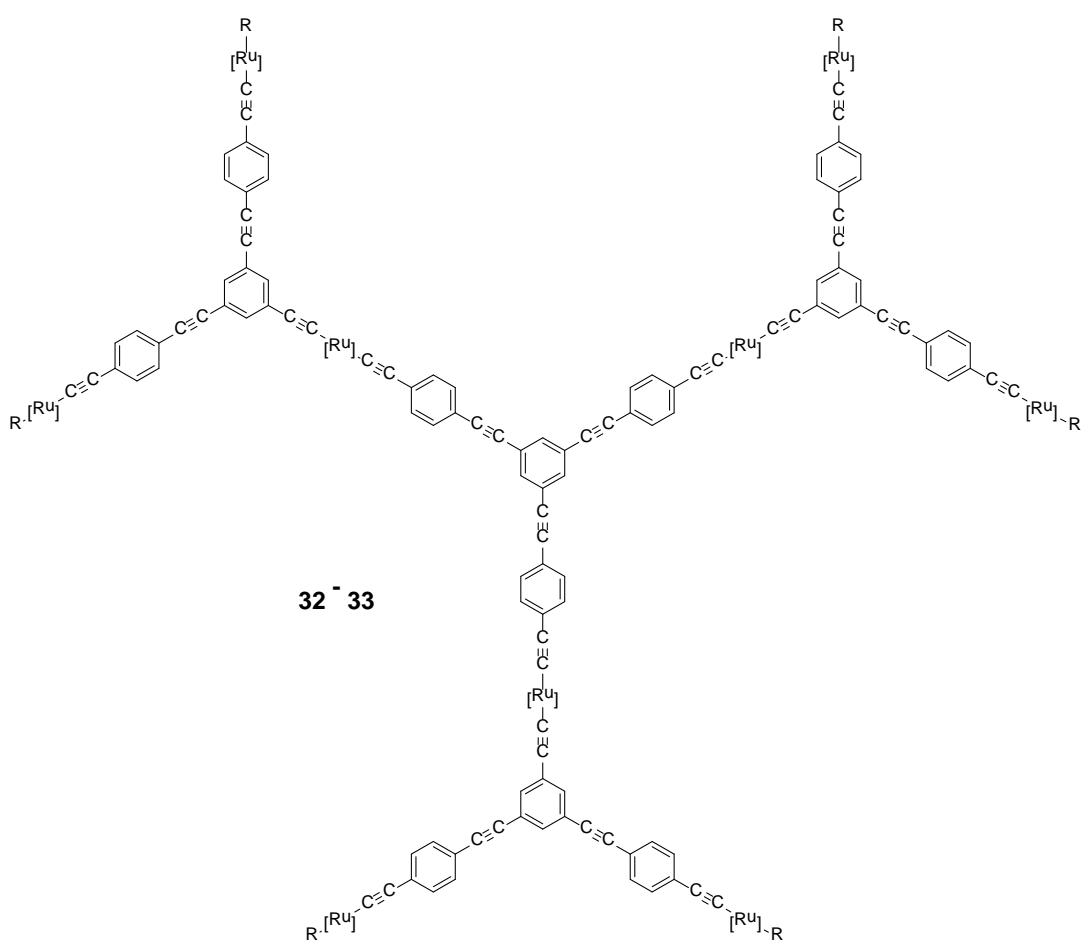

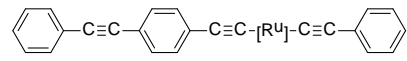

34

Figure 5. Complexes 20 - 34.

\begin{tabular}{|c|c|c|c|}
\hline complex & $\mathbf{R}$ & $\begin{array}{r}\sqrt{\left\langle\beta^{2}\right\rangle} \\
\left(10^{-30} \mathrm{esu}\right)\end{array}$ & $\begin{array}{c}\sqrt{\left\langle\beta_{0}^{2}\right\rangle} \\
\left(10^{-30} \mathrm{esu}\right)\end{array}$ \\
\hline
\end{tabular}




\begin{tabular}{lccc}
\hline $\mathbf{2 0}$ & $\mathrm{Br}$ & 6 & 4 \\
$\mathbf{2 1}$ & $\mathrm{I}$ & 9 & 5 \\
$\mathbf{2 2}$ & $\mathrm{C} \equiv \mathrm{CH}$ & 8 & 5 \\
$\mathbf{2 3}$ & $\mathrm{Cl}$ & 101 & 34 \\
$\mathbf{2 4}$ & $\mathrm{C} \equiv \mathrm{CPh}$ & 105 & 37 \\
$\mathbf{2 5}$ & $\mathrm{C} \equiv \mathrm{C}-4-\mathrm{C}_{6} \mathrm{H}_{4} \mathrm{NO}_{2}$ & 900 & 182 \\
$\mathbf{2 6}$ & $\mathrm{C} \equiv \mathrm{CPh}$ & 104 & 37 \\
$\mathbf{2 7}$ & $\mathrm{C} \equiv \mathrm{C}-4-\mathrm{C}_{6} \mathrm{H}_{4} \mathrm{NO}_{2}$ & 1120 & 220 \\
$\mathbf{2 8}$ & $\mathrm{SiMe}$ & 8 & 4 \\
$\mathbf{2 9}$ & {$[\mathrm{Ru}] \mathrm{Cl}$} & 94 & 32 \\
$\mathbf{3 0}$ & {$[\mathrm{Ru}]\left(\mathrm{C} \equiv \mathrm{CPh}_{3}\right.$} & 93 & 31 \\
$\mathbf{3 1}$ & {$[\mathrm{Ru}]\left(\mathrm{C} \equiv \mathrm{C}-4-\mathrm{C}_{6} \mathrm{H}_{4} \mathrm{NO}_{2}\right)$} & 1220 & 254 \\
$\mathbf{3 2}$ & $\mathrm{C} \equiv \mathrm{CPh}$ & 160 & 59 \\
$\mathbf{3 3}$ & $\mathrm{C} \equiv \mathrm{C}-4-\mathrm{C} 6 \mathrm{H}_{4} \mathrm{NO}_{2}$ & 1880 & 350 \\
$\mathbf{3 4}$ & $/$ & 34 & 14 \\
\hline
\end{tabular}

Table 4. Second-order NLO responses by HRS at $1064 \mathrm{~nm}\left([\mathrm{Ru}]=\operatorname{trans}-\left[\mathrm{Ru}\left(\kappa^{2}-\right.\right.\right.$ dppe $\left.\left.)_{2}\right]\right)$. The rotational averages $\left\langle\beta^{2}\right\rangle$ correspond to all non-zero tensor components. For dipolar molecules, only the diagonal tensor component along the molecular 3-axis, $\beta_{333}$, is significant, and $\beta=\sqrt{ }(6 / 35) \beta_{333}$. For octupolar molecules with $D_{3 h}, T_{d}$ or $D_{2 d}$ symmetry, the only non-zero hyperpolarizability tensor component is $\beta_{123}$. The octupolar complexes in Figure 5 formally have $D_{3 h}$ symmetry, and $\beta=\sqrt{ }(8 / 21) \beta_{123}$ [34].

The presence of the metal is crucial to the quadratic NLO merit (there is an appreciable increase in $\beta_{\mathrm{HRS}}$ 10 proceeding from the organic acetylenes 22 and $\mathbf{2 8}$ to the corresponding organometallic complexes 23 and 29). However, extending the delocalized $\pi$-system through the metal (progressing from 23 to 24 and 
29 to 30) does not increase $\beta$, which is consistent with the trans-phenylalkynyl ligand acting largely as a $\pi$-donor ligand to the ruthenium, rather than the ruthenium acting as a conduit to extend the $\pi$ delocalization. Complex $\mathbf{3 4}$ is a linear fragment of the octupolar complex 30, and, not surprisingly, progressing from 34 to $\mathbf{3 0}$ results in a three-fold increase in oscillator strength of the UV-vis band

5 assigned to the MLCT transition. The $\beta$ value of the two-dimensional complex $\mathbf{3 0}$ is much improved compared to that of the one-dimensional complex 34, with little loss of optical transparency accompanying the large increase in $\beta$.

Dendrimer 32 results from the coupling of $\mathbf{2 6}$ and $\mathbf{2 9}$ and, although its $\square$ quadratic NLO coefficient $\square$ s 10 larger than that of either of its constituents, it is not dramatically so, despite the fact it is a nine-metalcenter complex compared to the precursors which contain three or two metal atoms. This suggests that a "dendrimer approach" may not be the best way to maximize quadratic NLO merit. Improvements in nonlinearity in dipolar systems are usually accompanied by a decrease in optical transparency, but this is not necessarily the case for multi-polar systems; no loss in transparency is seen on progressing from 1530 to 32, so while the gain in nonlinearity on dendrimer generation increase is modest, there is compensation in maintenance of transparency. The $\beta_{\mathrm{HRS}}$ values for $\mathbf{3 0}$ and $\mathbf{3 2}$ are very large for multipolar compounds optically transparent at the second-harmonic, and therefore with diminished resonance enhancement.

20 The $\beta$ values of the nitro-containing complexes are an order of magnitude greater that those of their nonnitro analogues, but are resonance enhanced due to the proximity of the absorption band associated with the MLCT transition to the second-harmonic wavelength of $532 \mathrm{~nm}$. A $50 \%$ gain in $\beta$ value is found on progressing from the three-metal-center zero-generation dendrimer $\mathbf{3 1}$ to the nine-metal-center firstgeneration dendrimer 33, the $\beta$ value at $1064 \mathrm{~nm}$ for the latter $\left(1880 \times 10^{-30}\right.$ esu) being particularly large 
for a formally octupolar molecule. For the complexes containing nitro groups, no significant changes in the trends found in the experimental data are seen in the calculated static $\beta$ values. The $\beta_{0}$ value for 33 is amongst the largest obtained for an organometallic complex, or indeed any molecule with formally octupolar symmetry.

5

$\beta$ is a tensor and, in fact, can afford information about the symmetry of the molecules being measured. This is achieved by depolarization measurements, which involve measuring the intensity of the scattered second-harmonic light which is parallel, $\mathbf{I}_{\mathbf{Z Z}}^{2 \omega}$, and that which is perpendicular, $\mathrm{I}_{\mathrm{Zx}}^{2 \omega}$, to the plane of the incident polarized laser beam. The ratio of these two quantities depends on the molecular symmetry and 10 for purely dipolar molecules with $C_{2 v}$ symmetry:

$$
\rho=\frac{I_{Z Z}^{2 \omega}}{I_{Z X}^{2 \omega}}=5
$$

while for purely octupolar molecules with $D_{3 h}, T_{d}$ or $D_{2 d}$ symmetry:

$$
\rho=\frac{I_{Z Z}^{2 \omega}}{I_{Z X}^{2 \omega}}=1.5 .
$$

Depolarization measurements were carried out on 29 and 30. While the depolarization ratio of $1.4 \pm 0.2$ 15 for complex 29 is consistent with purely octupolar symmetry, that of complex $30(2.1 \pm 0.1)$ suggests deviation from octupolar symmetry, most likely a lack of coplanarity of the peripheral phenylethynyl groups with the central $\pi$-system (a decrease in molecular symmetry would result in an increase in $\rho$ because dipolar contributions to the first hyperpolarizability are introduced). Thus, this NLO technique suggests that discussion of molecules larger than $\mathbf{2 9}$ (for example, the first-generation dendrimers $\mathbf{3 2}$ and 20 33) solely in octupolar terms is inappropriate. 


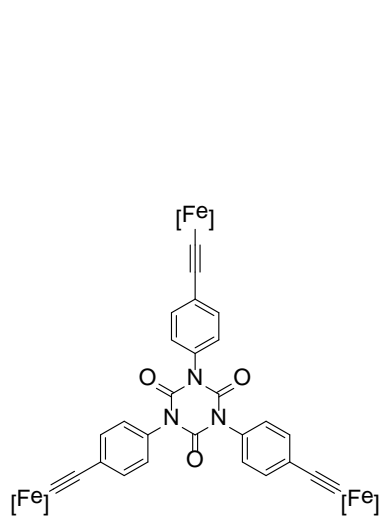

35

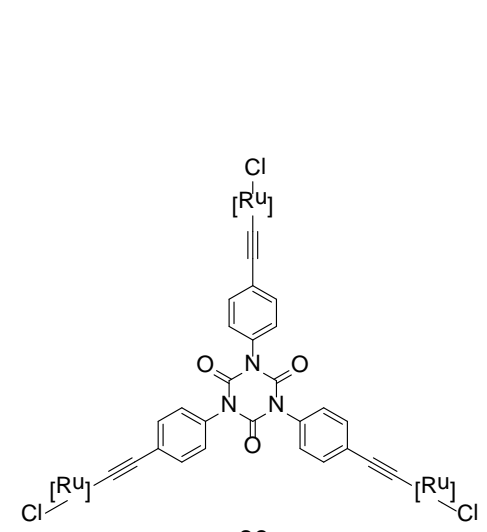

36

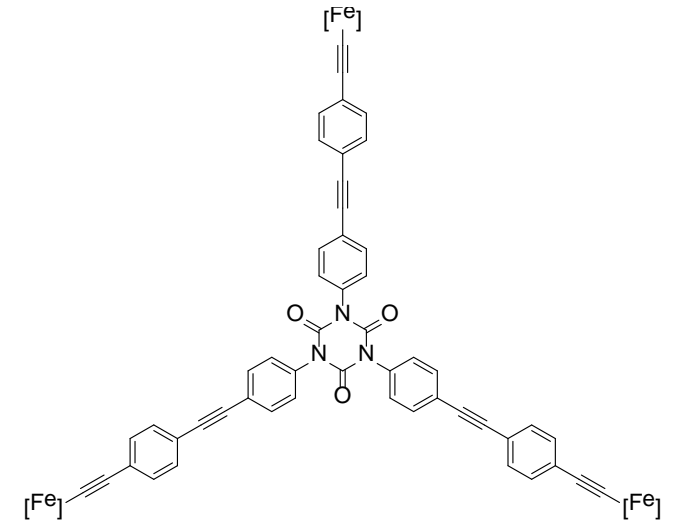

37

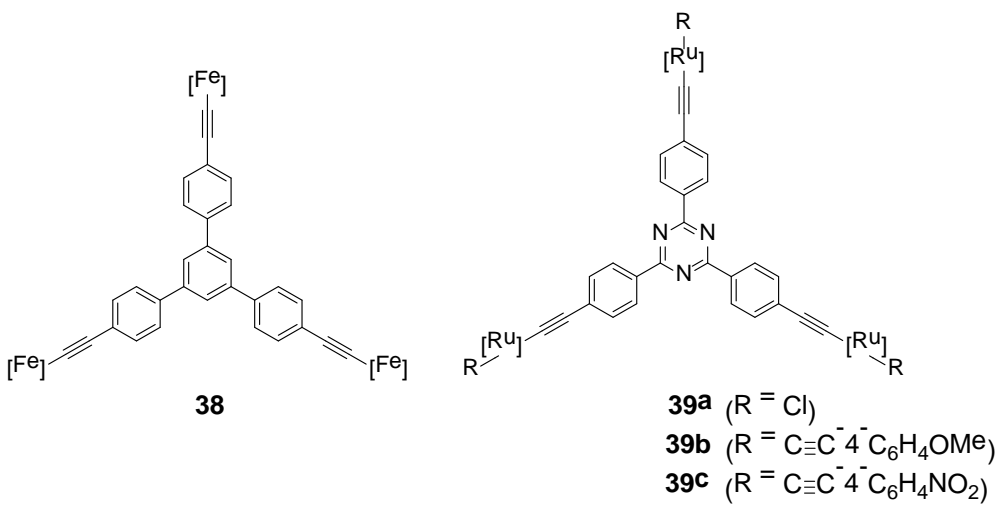

Figure 6. Complexes 35 - $39\left([\mathrm{Fe}]=\mathrm{Fe}\left(\kappa^{2}-\mathrm{dppe}\right)\left(\eta^{5}-\mathrm{C}_{5} \mathrm{Me}_{5}\right) ;[\mathrm{Ru}]=\right.$ trans- $\left.\left.\left[\mathrm{Ru}\left(\kappa^{2}-\mathrm{dppe}\right)_{2}\right]\right)\right)$.

More recently, the hyperpolarizabilities of the octupolar complexes 35-38 in Figure 6 have also been 5 assessed by HRS at $1907 \mathrm{~nm}$ (Table 5) [36]. While these values appear larger than those of 29-31, compounds of similar size, comparison is problematic because the data were determined on different experimental setups at different wavelengths and relative to different references. However, the data are larger in magnitude than those reported for the related complexes 39a-c $\left(\beta_{1064}=457 \times 10^{-30}\right.$ esu, $505 \times$ $10^{-30}$ esu, $558 \times 10^{-30}$ esu, respectively) [37], attesting to a high activity for these iron-containing 10 octupoles, the data being significantly larger than that of the organic precursors. Extension of the peripheral arms, when proceeding from 35 to 37 , results in only a modest increase in $\beta$ and $\beta_{0}$, in line with a bridge length-dependent saturation of the hyperpolarizability, while there is only a modest dependance on the nature of the peripheral organometallic group (comparing 35 and 36). Finally, 
comparison of $\mathbf{3 5}$ and $\mathbf{3 8}$ reveals that replacement of the phenyl core by an isocyanurate unit has only a modest effect on hyperpolarizabilities, but affords slightly increased tranparency in the visible range.

\begin{tabular}{lccc}
\hline complex & $\begin{array}{c}\lambda_{\max } \\
(\mathrm{nm})\end{array}$ & $\begin{array}{c}\sqrt{\left\langle\beta^{2}\right\rangle} \\
\left(10^{-30} \mathrm{esu}\right)\end{array}$ & $\begin{array}{c}\sqrt{\left\langle\beta_{0}^{2}\right\rangle} \\
\left(10^{-30} \mathrm{esu}\right)\end{array}$ \\
\hline $\mathbf{3 5}$ & 400 & 322 & 254 \\
$\mathbf{3 6}$ & 342 & 288 & 243 \\
$\mathbf{3 7}$ & 446 & 374 & 276 \\
$\mathbf{3 8}$ & 422 & 312 & 232
\end{tabular}

Table 5. Second-order NLO responses ( $\pm 15 \%$ ) by HRS at $1907 \mathrm{~nm}$. $\beta$ o values are derived from UV data assuming a degenerate three-level model [13].

\section{Cubic NLO studies}

\subsection{General comments}

10

There have been a significant number of studies of the cubic NLO properties of Group 8 metal alkynyl complexes in the past decade, the major foci being multi-polar charge distributions and an emphasis on switching cubic NLO properties. This section summarizes progress with complexes in their resting states, while section 5.3. highlights (primarily electrochemical) switching studies.

Less is known about designing efficient cubic NLO materials than their quadratic NLO counterparts. Nevertheless, structure-activity relationships have been established for third-order NLO effects. Several classes of active structures have been extracted from these studies that possess the same characteristics: they have polarizable $\pi$-electrons and low-energy intramolecular charge transfer, but they differ in the 
nature of their multi-polar charge distributions. The first compound type has the dipolar composition exhibited by many efficient second-order NLO-active compounds: a donor and an acceptor group linked together by an unsaturated bridge possessing polarizable $\pi$-electrons (Figure 7). The second type of structure consists of two acceptor or donor groups linked by an unsaturated $\pi$-delocalized bridge; 5 variations exist with the intercalation of a donor group between the two terminal acceptor groups (and vice versa) (Figure 8). The third type of cubic NLO-active compounds are those possessing octupolar geometries $\left(O_{h}, T_{d}, D_{n h} ; \mathrm{n}=3,4\right)$, some of which are shown in Figure $9[13,38]$.

10

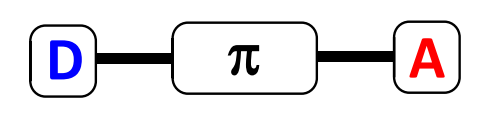

Figure 7. Dipolar composition of cubic NLO-active compounds.

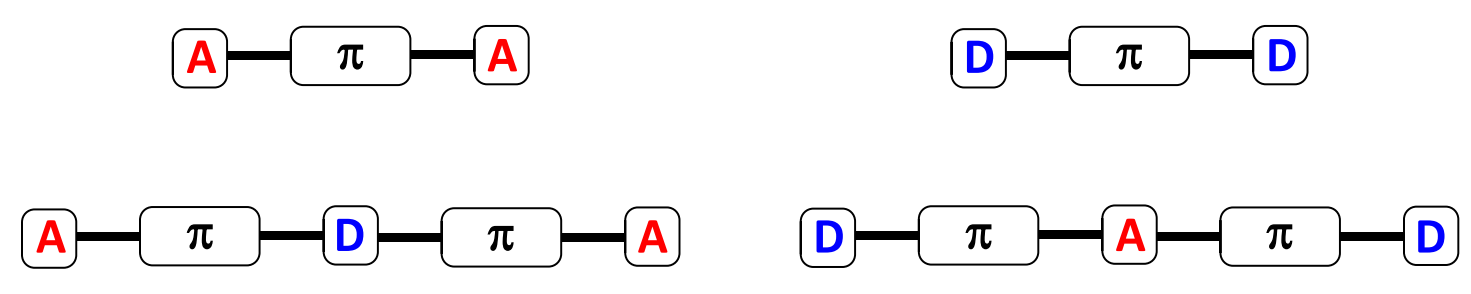

Figure 8. Quadrupolar compositions of cubic NLO-active compounds.

15
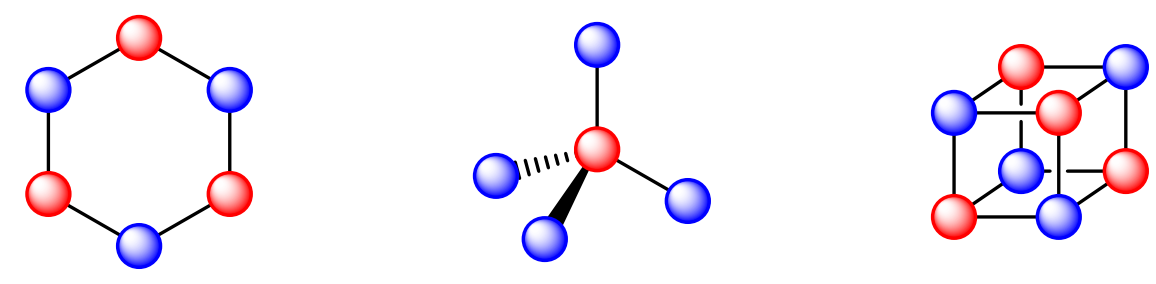

Figure 9. Octupolar compositions of cubic NLO-active compounds [13,38].

\section{4.2. Dipolar complexes}

The cubic NLO properties of small dipolar Group 8 metal alkynyl complexes had been assayed in the 1990s, values at a fixed wavelength of $800 \mathrm{~nm}$ typically being very low. More recent Z-scan studies at 
single wavelengths in the region 650-800 nm of alkynyl and alkenyl complexes 40 - 45 (Figure 10) [14,32,39-41], as well as degenerate four-wave mixing studies at $532 \mathrm{~nm}$ of the (poly)thiophene-bridged complexes 46 and 47 (Figure 11) [42,43] have confirmed this general observation. The well-established dependence of the NLO response as a function of the $\pi$-bridge length was verified in these series of D$5 \pi$-A complexes, with the metal center playing the role of the donor group, while barbiturate-terminated complexes were found to be less active than aldehyde-terminated analogues.

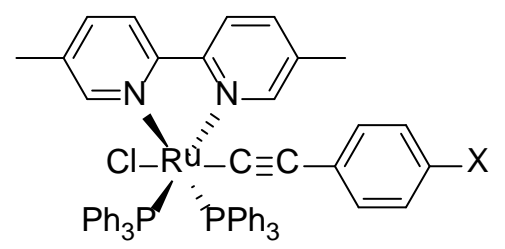

$40 a^{-} \mathrm{b}$

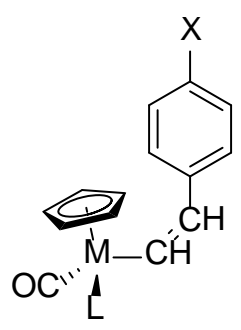

$41 a^{-} d$

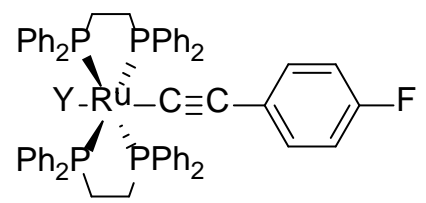

$42 a^{-} b$

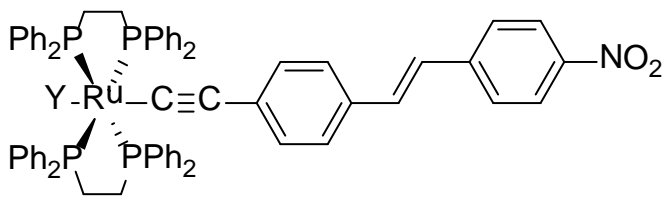

$4 a^{-} \mathrm{b}$

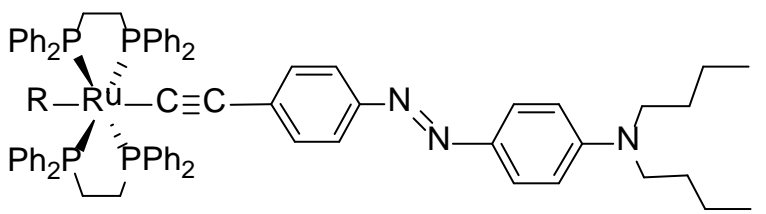

$45 \mathrm{a}^{-\mathrm{c}} \mathrm{c}$

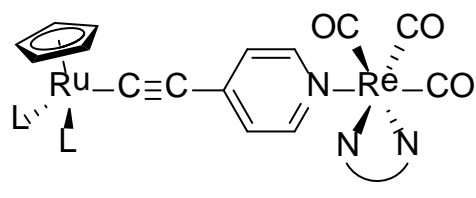

$44 a^{-} e$

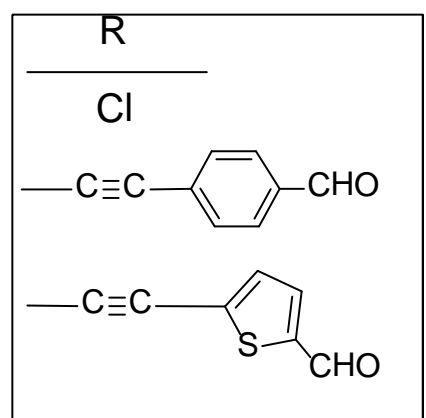

Figure 10. Alkynyl and alkenyl complexes $\mathbf{4 0}$ - $\mathbf{4 5}$ measured by Z-scan at specific wavelengths in the range $680-800 \mathrm{~nm}$. 


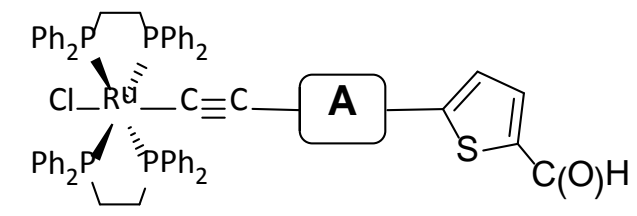

\section{$46^{-e} \mathrm{e}$}
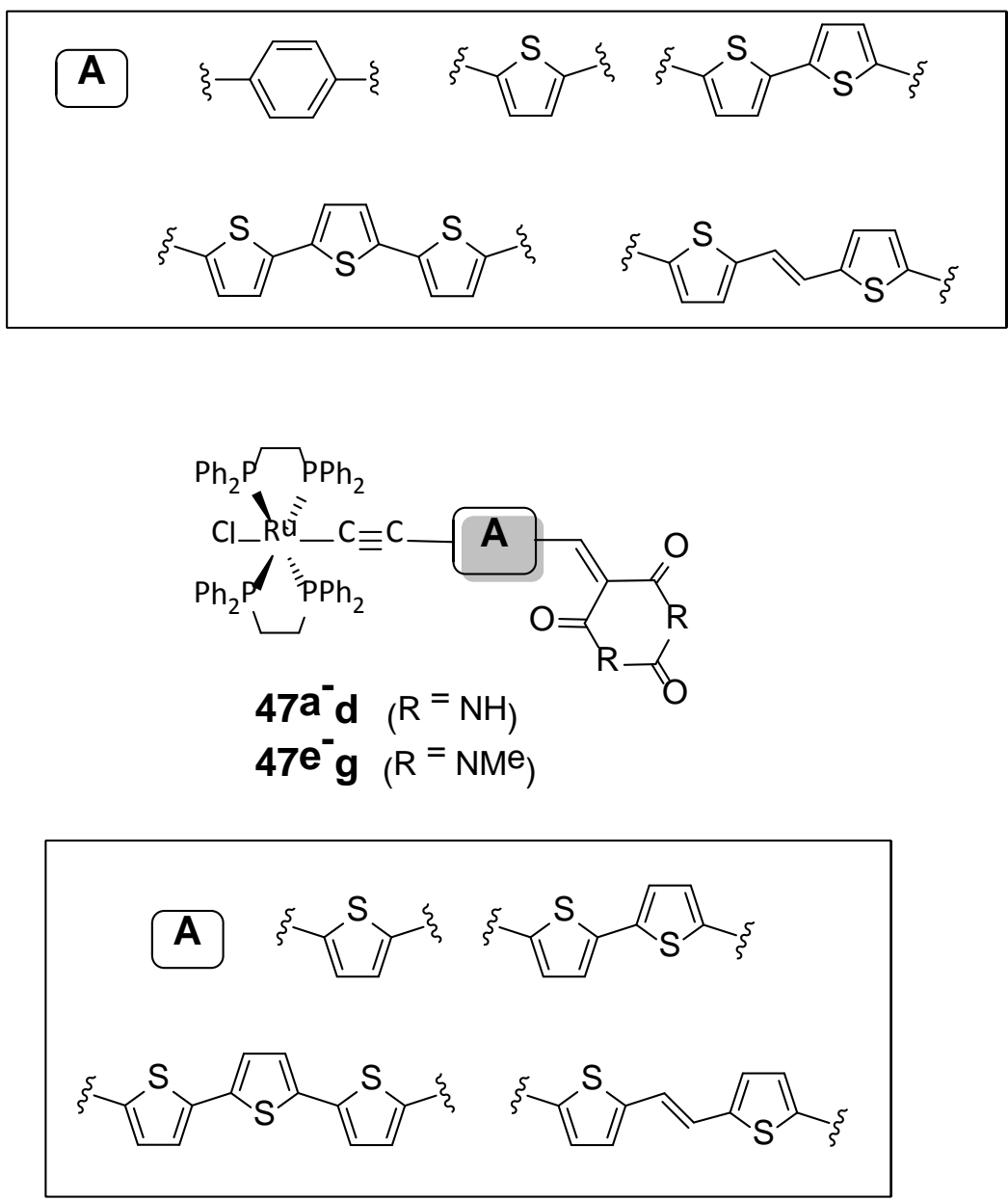

Figure 11.. Thiophene-containing complexes 46 - 47 measured at single wavelengths by DFWM and Z-scan.

5 Because cubic nonlinearities are wavelength dependent, such single wavelength studies almost certainly do not ascertain the maximal values. Z-scan studies on complexes $\mathbf{4 b}$ - $\mathbf{6 b}, \mathbf{7}-\mathbf{9}$ (Figure 2) across the spectral range 530-1500 $\mathrm{nm}$ revealed that 2PA maxima are in the range $840-940 \mathrm{~nm}$, with the largest 
value exhibited by the tri(phenyleneethynylene) complex $\mathbf{6 b}$ for which quadratic nonlinearity is also maximized [28].

\section{4.3. Quadrupolar complexes}

Z-scan studies at $750 \mathrm{~nm}$ of the centrosymmetric complexes trans-[( $\left.\eta^{5}-\mathrm{C}_{5} \mathrm{H}_{5}\right)(\mathrm{dppf}) \mathrm{Ru}(\mathrm{C} \equiv \mathrm{C}-4$ $\left.\left.\mathrm{C}_{5} \mathrm{H}_{4} \mathrm{~N}\right) \mathrm{PtCl}_{2}\left(\mathrm{NC}_{5} \mathrm{H}_{4}-4-\mathrm{C} \equiv \mathrm{C}\right) \mathrm{Ru}(\mathrm{dppf})\left(\eta^{5}-\mathrm{C}_{5} \mathrm{H}_{5}\right)\right] \quad(\mathbf{4 8}) \quad$ and $\quad$ trans, trans, trans-[( $\left.\kappa^{2}-\mathrm{dppm}\right)_{2} \mathrm{ClRu}-$ $\left.\left(\mathrm{C} \equiv \mathrm{CC}_{5} \mathrm{H}_{4} \mathrm{~N}-4\right) \mathrm{PdCl}_{2}\left(\mathrm{NC}_{5} \mathrm{H}_{4}-4-\mathrm{C} \equiv \mathrm{C}\right) \mathrm{RuCl}\left(\kappa^{2}-\mathrm{dppm}\right)_{2}\right]$ (49), together with their monoruthenium

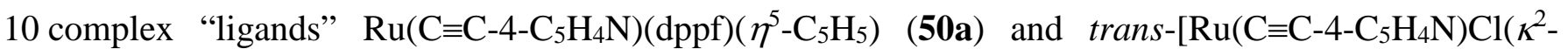
dppm) $)_{2}$ (50b) (Figure 12), revealed fifty-fold increases in $\gamma_{\text {imag }}$ and 2PA cross-sections on proceeding from the building blocks to the heterotrimetallic complexes at this wavelength (Table 6), although the trimetallic complexes exhibit optical absorption maxima close to the second-harmonic wavelength of the incident laser. With 18-electron Ru centers at the peripheries and 16-electron Group 10 metal atoms 15 at the centers, the complexes can be considered to have a D- $\pi$-A- $\pi$-D composition (Figure 12) [44]. 


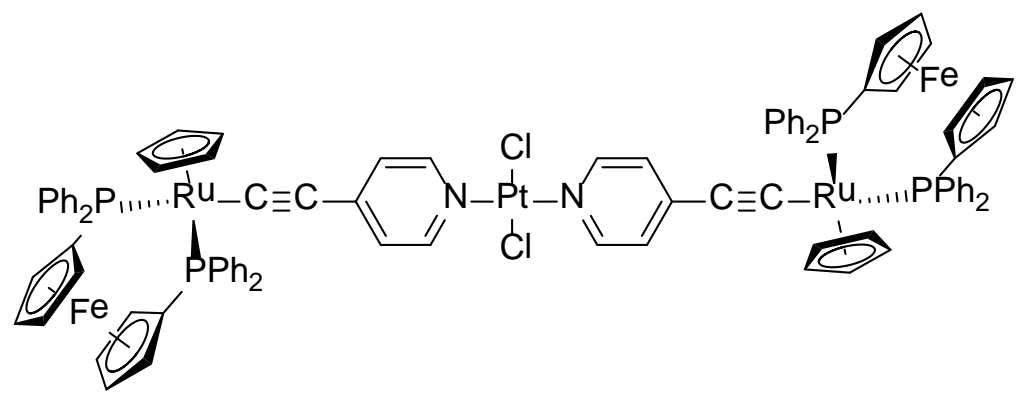

48

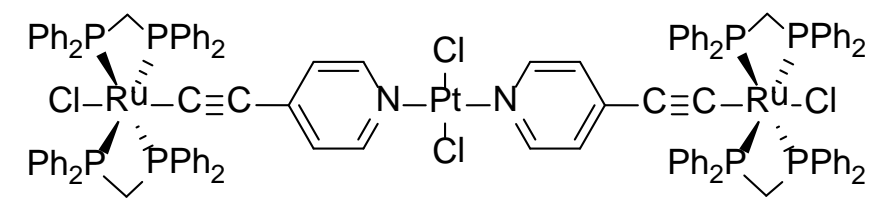

49

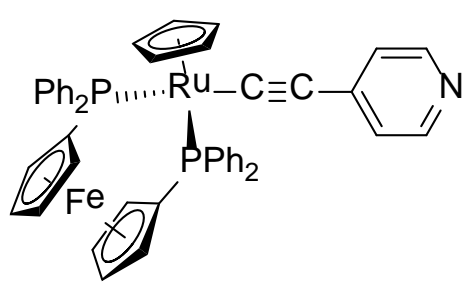

$50 a$

Figure 12. Quadrupolar alkynyl complexes 48, 49, 50a-b.

\begin{tabular}{clc}
\hline complex & $\begin{array}{c}\lambda_{\max } \\
(\mathrm{nm})\end{array}$ & $\begin{array}{c}\gamma \square \square \\
\left(10^{-36} \mathrm{esu}\right)\end{array}$ \\
\hline $\mathbf{4 8}$ & 393 & $600 \pm 200$ \\
$\mathbf{4 9}$ & 385 & $800 \pm 100$ \\
$\mathbf{5 0 a}$ & 339 & $10 \pm 4$ \\
$\mathbf{5 0 b}$ & 336 & $13 \pm 10$ \\
\hline
\end{tabular}

Table 6. Cubic NLO data (Z-scan) for complexes 48, 49, 50a-b at $750 \mathrm{~nm}$ [44]. 5

Porphyrins have been of longstanding interest in nonlinear optics due to their large delocalizable $\pi$ systems, robust nature, and biocompatibility. Recently, porphyrins have been hybridized with Group 8 metal alkynyl units and the cubic NLO properties of the resultant assemblies have been examined (Figure 13) $[45,46]$. The $2 \mathrm{PA}$ cross-sections of the peripherically metallated $\mathrm{Zn}(5,10,15,20$-tetraarylporphyrin) 10 complexes 51 - 53 were assayed across a broad spectral range, displaying maximal values in the regions 710-770 $\mathrm{nm}$ and 1000-1300 nm (Table 7). In the lower wavelength region, the complex $\mathbf{5 1}$ is most 
efficient (10 $200 \mathrm{GM}$ at $740 \mathrm{~nm}$ ), whereas in the long wavelength region, the complexes 52a-c exhibit the greatest efficiency (ca. $1400 \mathrm{GM})$.

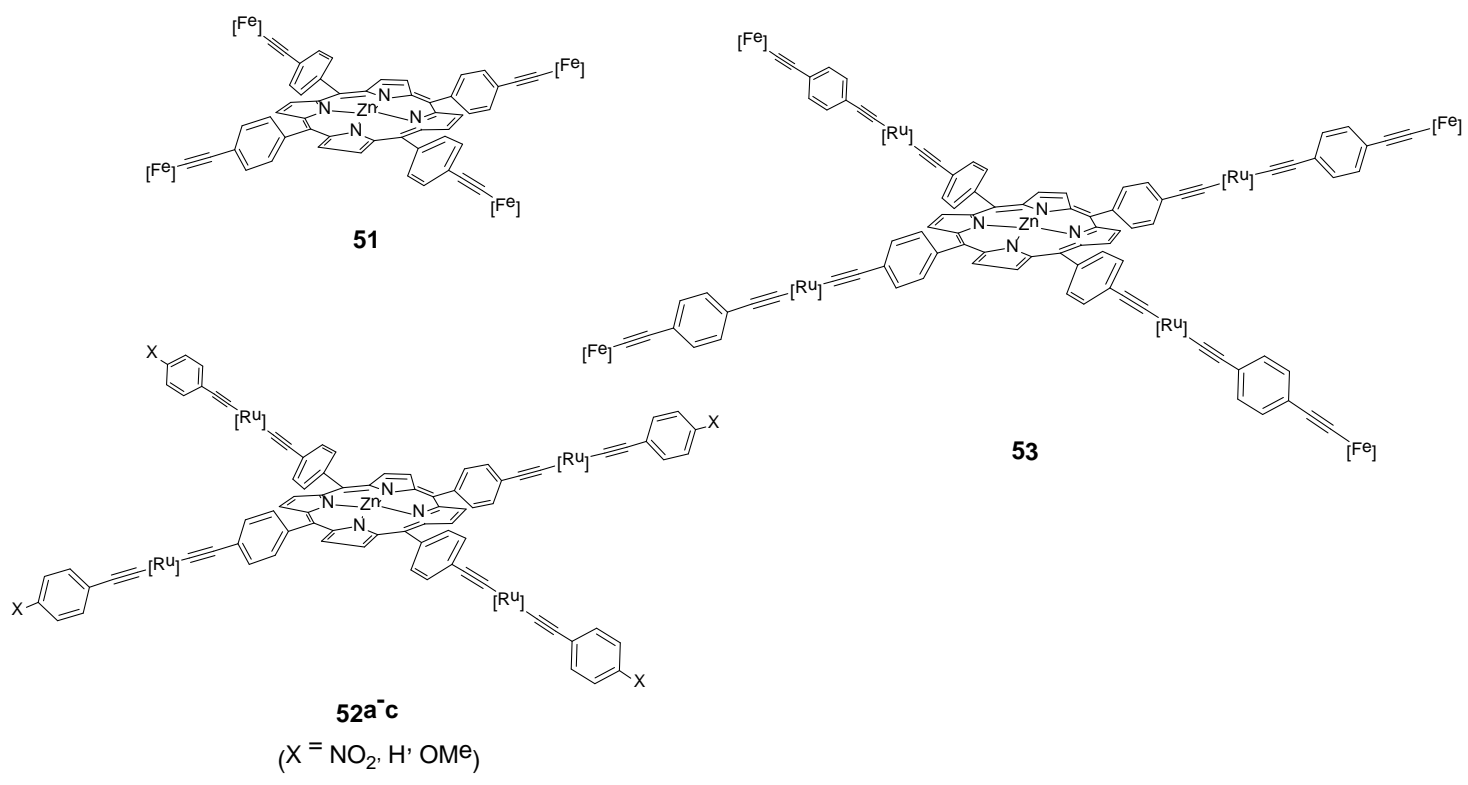

Figure 13. Tetraphenylporphyrin-based assemblies 51, 52a-c and $53\left([\mathrm{Fe}]=\mathrm{Fe}\left(\kappa^{2}-\mathrm{dppe}\right)\left(\eta^{5}-\mathrm{C}_{5} \mathrm{Me}_{5}\right)\right.$;

$\left.[\mathrm{Ru}]=\operatorname{trans}-\left[\mathrm{Ru}\left(\kappa^{2}-\mathrm{dppe}\right)_{2}\right]\right)$. 


\begin{tabular}{|c|c|c|c|c|c|c|c|c|}
\hline \multirow{3}{*}{ complex } & \multicolumn{2}{|r|}{$1^{\text {st }} \max$} & \multicolumn{2}{|r|}{$2^{\text {nd }} \max$} & \multicolumn{2}{|c|}{$3^{\text {rd }} \max$} & \multicolumn{2}{|r|}{$1^{\mathrm{st}} \min$} \\
\hline & $\lambda_{\max }$ & $\sigma_{2, \mathrm{eff}}$ & $\lambda_{\max }$ & $\sigma_{2, \mathrm{eff}}$ & $\lambda_{\max }$ & $\sigma_{2, \mathrm{eff}}$ & $\lambda_{\max }$ & $\sigma_{2 \mathrm{eff}}$ \\
\hline & $(\mathrm{nm})$ & {$[\mathrm{GM}]$} & $(\mathrm{nm})$ & {$[\mathrm{GM}]$} & $(\mathrm{nm})$ & {$[\mathrm{GM}]$} & (nm) & {$[\mathrm{GM}]$} \\
\hline $52 a$ & 530 & $6000 \pm 500$ & 770 & $6000 \pm 3000$ & 1000 & $1500 \pm 500$ & 620 & $-4500 \pm 200$ \\
\hline $52 b$ & I & I & 710 & $4800 \pm 500$ & 1300 & $1400 \pm 500$ & 595 & $-2800 \pm 600$ \\
\hline
\end{tabular}

${ }^{a}$ Not determined due to sample photodegradation.

Table 7. Extremal values of the effective two-photon absorption cross-sections ( $\sigma_{2, \text { eff }}$ by Z-scan in $\mathrm{CH}_{2} \mathrm{Cl}_{2}[45,46]$. 
$\pi$-Bridge lengthening was found to have a negligible effect on the location of the 2PA maxima of systematically varied centrosymmetric oligo(p-phenyleneethynylene)-linked ruthenium alkynyl complexes 54-59 (Figure 14) [47]. These complexes have a D- $\pi$-D composition (Figure 8) and their synthesis necessitated incorporation of hexyloxy solubilizing groups which are not electronically innocent; the linear absorption maxima red-shift on their introduction, although the location of the aforementioned 2PA maxima are invariant (Table 8). The $\sigma_{2 \text {,max }}$ values increase slightly with increasing chain length, and also on embedding the Ru atoms within the OPE unit of a fixed chain length, the most efficient complex (56; $1050 \mathrm{GM})$ possessing a nona(phenyleneethynylene) (9PE) chain similar to 55c (630 GM), but with a 2PE-[Ru]-5PE[Ru]-2PE composition for the former rather than the [Ru]-9PE-[Ru] formulation of the latter (for ligated ruthenium $[\mathrm{Ru}]$ ). 


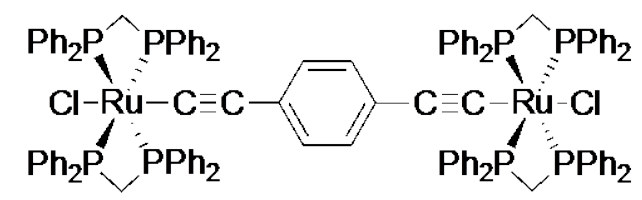

54

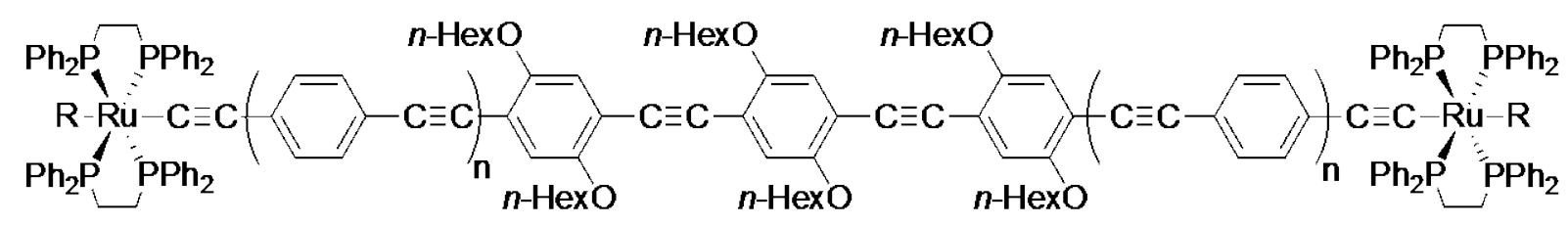

55a, $\mathbf{n}=0, \mathrm{R}=\mathrm{Cl}$

$55 b, n=1, R=C l$

$55 \mathrm{c}, \mathrm{n}=3, \mathrm{R}=\mathrm{Cl}$

56, $n=1, R=C \equiv C-4-C_{6} H_{4} C=C P h$

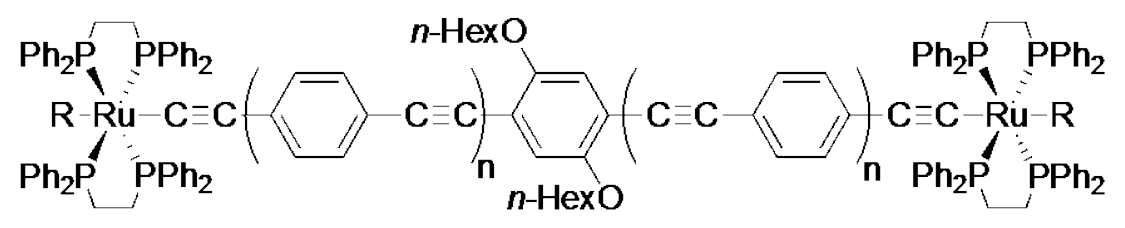

$$
\begin{aligned}
& \text { 57, } n=1, R=C \equiv C P h \\
& 58, n=1, R=C \equiv C-4-C_{6} H_{4} C \equiv C P h \\
& 59, n=3, R=C l
\end{aligned}
$$

Figure 14. Quadrupolar alkynyl complexes 54-59.

\begin{tabular}{lcc}
\hline complex & $\begin{array}{c}v_{\max } \\
\left(\mathrm{cm}^{-1}\right)\end{array}$ & $\begin{array}{c}\sigma_{2, \max } \\
(\mathrm{GM})\end{array}$ \\
\hline $\mathbf{5 4}$ & 28400 & 600 \\
$\mathbf{5 5 a}$ & 22200 & 530 \\
$\mathbf{5 5 b}$ & 22800 & 580 \\
$\mathbf{5 5 c}$ & 23500 & 630 \\
$\mathbf{5 6}$ & 23300 & 1050 \\
$\mathbf{5 7}$ & 23400 & 300 \\
$\mathbf{5 8}$ & 24100 & 290 \\
$\mathbf{5 9}$ & 24300 & 730 \\
\hline
\end{tabular}

Table 8. Two-photon absorption data (open-aperture Z-scan) for complexes 54 - 59 [47]. 


\subsection{Octupolar complexes}

There are several octupolar geometries depicted in Figure 9, but 1,3,5-substitution of a benzene ring has been by far the most extensively explored octupolar geometry in nonlinear optics. As with the other geometries highlighted above, lack of ready access to tuneable laser systems resulted in earlier studies reporting data at single wavelengths only, and this continued into the past decade. For example, Z-scan studies at $800 \mathrm{~nm}$ of a selection of phenyleneethynylenebased dendrimers peripherally functionalized by ligated ruthenium centers revealed the most cubic NLO-efficient at that wavelength (and the only saturable absorber) to be 1,3,5-(3,5$\left\{\text { trans- }\left[\left(\kappa^{2} \text {-dppe }\right)_{2}\left(\mathrm{O}_{2} \mathrm{NC}_{6} \mathrm{H}_{4}-4-\mathrm{C} \equiv \mathrm{C}\right) \mathrm{Ru}(\mathrm{C} \equiv \mathrm{C}]\right\}_{2} \mathrm{C}_{6} \mathrm{H}_{3}-1-\mathrm{C} \equiv \mathrm{CC}_{6} \mathrm{H}_{4}-4-\mathrm{C} \equiv \mathrm{C}\right)_{3} \mathrm{C}_{6} \mathrm{H}_{3} \quad$ (60; Figure 15) [48], an observation that prompted the first complete cubic NLO spectral dependence study of an inorganic complex on this compound [48,49], revealing the maximal positive value of the 2PA cross-section to be at $c a .1000 \mathrm{~nm}$ (4000 GM). Femtosecond Z-scan studies at $800 \mathrm{~nm}$ of first-generation phenyleneethynylene-based dendrimers revealed a $c a$. fourfold increase in cubic nonlinearity in proceeding from peripheral $\mathrm{Ru}_{6}$ metallation $(\mathbf{6 1})\left(|\gamma|=1600 \pm 2400 \times 10^{-}\right.$ ${ }^{36}$ esu) to peripheral $\mathrm{Ru}_{6} /$ internal $\mathrm{Pt}_{3}(\mathbf{6 2})$ metallation $\left(|\gamma|=7200 \pm 2900 \times 10^{-36}\right.$ esu) [50]. 

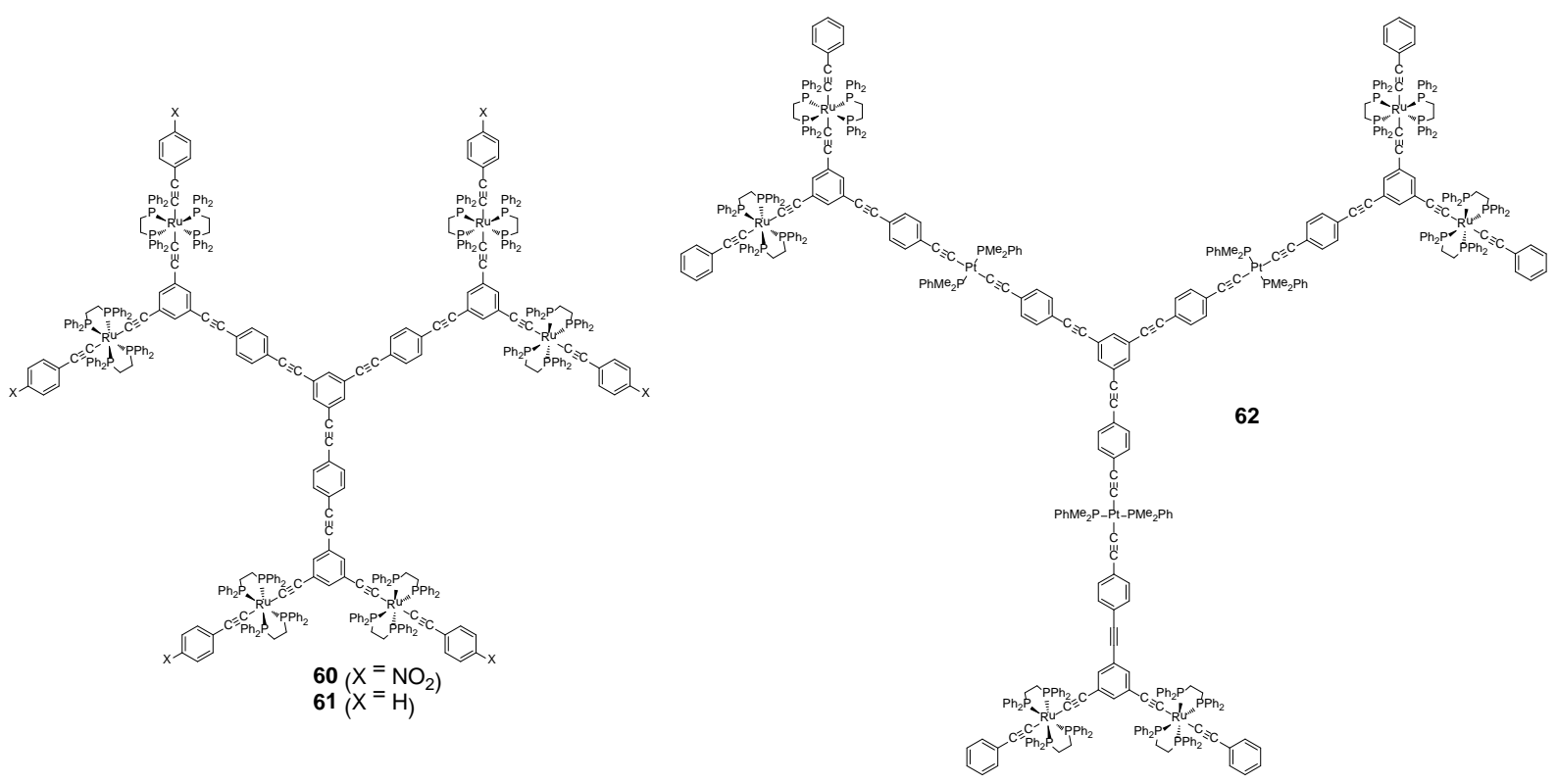

Figure 15. Dendritic complexes 60 - 62.

The second NLO spectral dependence study of an inorganic complex by Z-scan was carried out on the first-generation peripherally nitro-functionalized dendrimer 33 (Figure 5) [51]. In addition to possessing a 2PA maximum centered at $c a .750 \mathrm{~nm}\left(\sigma_{2}=3500 \mathrm{GM}\right), 33$ exhibits three-photon absorption (3PA) with a maximum centered at ca. $1200 \mathrm{~nm}\left(\sigma_{3}=1.5 \times 10^{-77} \mathrm{~cm}^{6}\right.$ $\mathrm{s}^{2}$ ). The 2PA and the 3PA maxima are slightly blue-shifted from twice (2PA) and three times (3PA) the wavelength of the one-photon absorption maximum corresponding to charge-transfer within the large delocalizable phenyleneethynylene-based $\pi$-manifold in the interior of the dendrimer [51]. Subsequent spectral dependence studies of 29-32 revealed significant 3PA at telecommunications wavelengths for 29-31, in addition to that previously observed for 33; 3PA cross-sections increase on introduction of nitro substituent (proceeding from $\mathbf{3 0}$ to $\mathbf{3 1}$ and $\mathbf{3 2}$ to 33) and dendrimer generation increase (proceeding from 31 to 33) [52].

$\mathrm{N}$-cored analogues were also examined, the rationale being that the planarity at the $s p^{2}$ hybridized nitrogen may improve $\pi$-delocation and optical nonlinearity [53]. Similar to 33, 
spectral dependence studies of the cubic nonlinearity revealed 2PA behavior at wavelengths below $1000 \mathrm{~nm}$, the maximal values being consistent with an NLO dendritic effect (a nonlinear increase in nonlinearity upon increasing dendrimer generation), while at wavelengths above $1000 \mathrm{~nm}$, the data are consistent with 3PA-induced photochemistry. The 2PA cross-sections of these organometallic dendrimers are much larger than those of comparable N-cored organic dendrimers, and this increased performance is maintained when the outcomes are scaled by “effective number of (delocalizable) electrons”, molecular weight, molecular volume, or even the cost of production [54,55].

A similar dendritic effect was observed in proceeding from the stilbene-based zero-generation dendrimer 63 to the first-generation example 64 (Figure 16) [56-58]; the cubic nonlinearity increases seven-fold when measured at $800 \mathrm{~nm}$ (from $2000 \times 10^{-36}$ esu to $14000 \times 10^{-36} \mathrm{esu}$ ) and four-fold at $600 \mathrm{~nm}$ (from $2800 \times 10^{-36}$ esu to $12000 \times 10^{-36}$ esu), although there is only a threefold increase in the number of ruthenium centers. Similar to the dendrimers above, complex 64 also shows a significant nonlinear absorption coefficient at a telecommunicationsrelevant wavelength $(1300 \mathrm{~nm})$. 

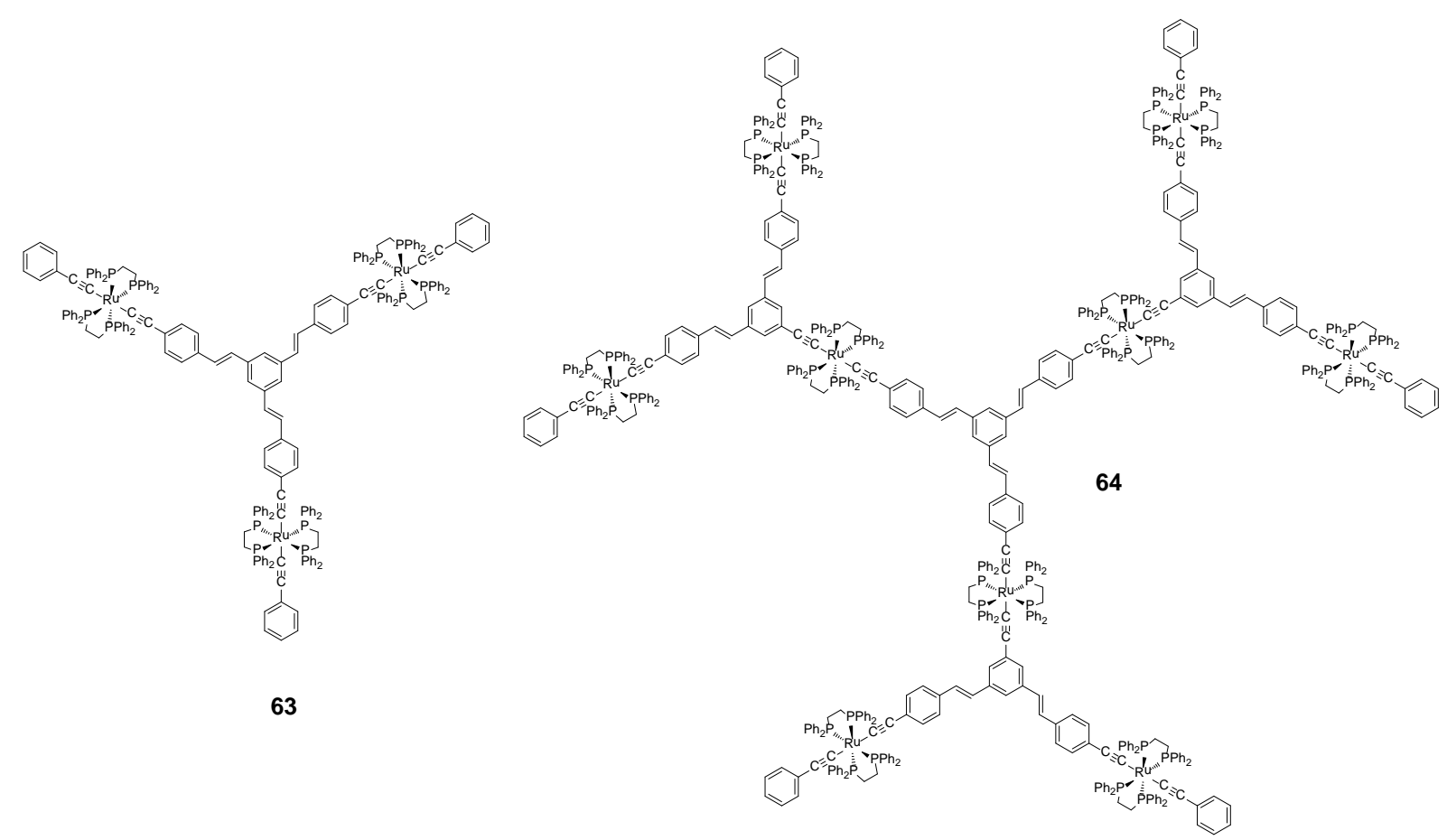

Figure 16. Zero- and first-generation dendrimers 63 and 64.

Structurally related zero-, first-, and second-generation ruthenium alkynyl dendrimers were recently assessed, one reason being to examine whether the NLO dendrimer effect seen for several pairs of complexes in proceeding from zero- to first-generation persists on proceeding to second-generation dendrimers [59]. The maximal 2PA values for the zero-generation 30 (370 GM at $810 \mathrm{~nm}$ ), first-generation $\mathbf{6 5}$ (11500 GM at $750 \mathrm{GM}$ ), and second-generation dendrimers 66 (29000 GM at $800 \mathrm{~nm}$ ) with 3, 9, and 21 ruthenium centers (Figure 17), respectively, do increase nonlinearly, whether scaled by number of metal centers, molecular weight, or effective number of delocalizable electrons. The dramatic increase seen from zeroto first-generation dendrimer is, however, attenuated on proceeding to second-generation dendrimer. 


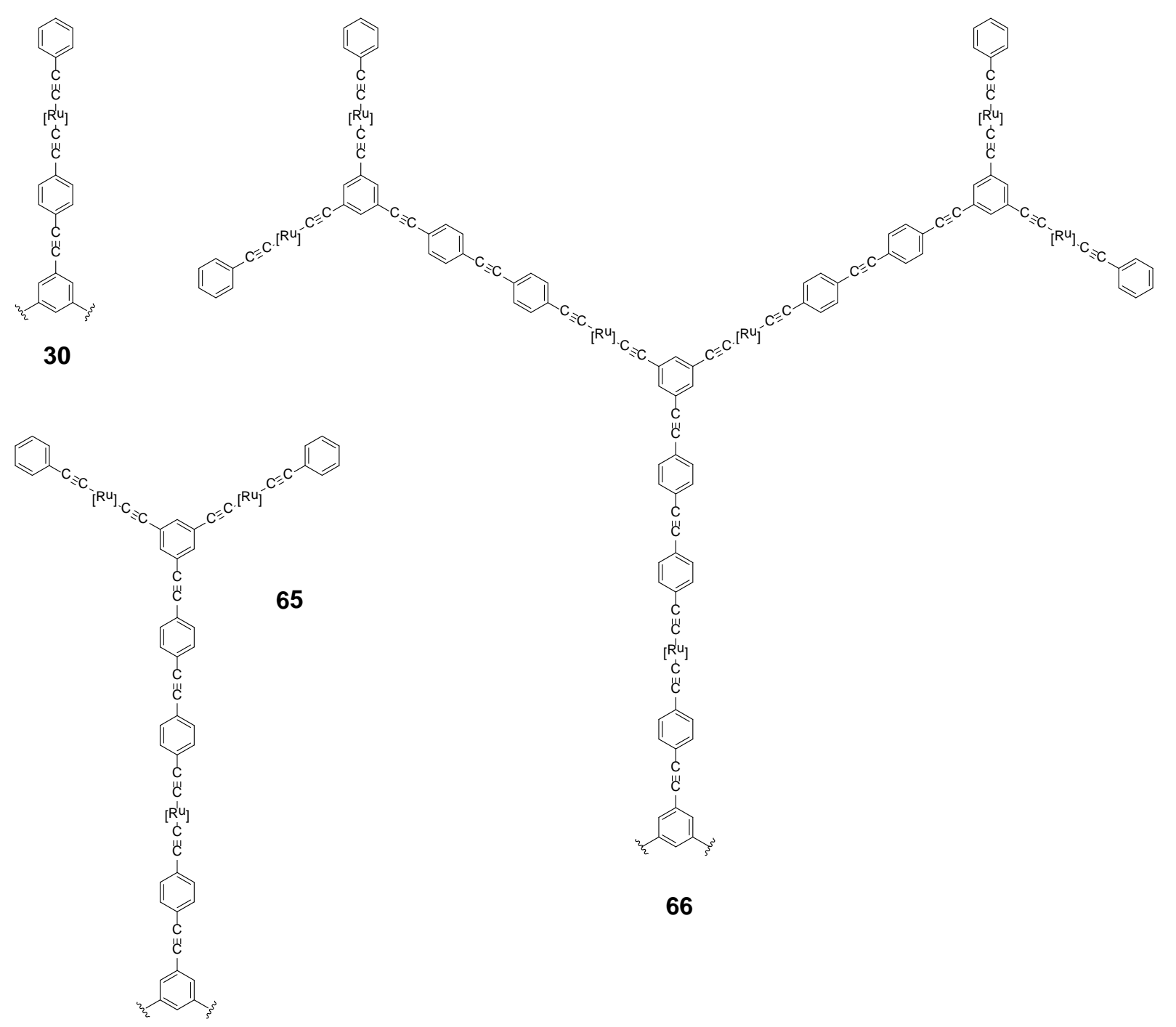

Figure 17. Successive generations of dendritic complexes 30,65 and $\mathbf{6 6}$. The wavy lines denote the two other identical branches of the dendrimers. $[\mathrm{Ru}]=\left[\mathrm{Ru}\left(\kappa^{2}-\mathrm{dppe}\right)_{2}\right]$.

\section{Switching NLO properties}

\subsection{General comments}

The incentive to switch from (conventional) electrical treatment towards all optical treatment of information is partly driven by the gain in speed, because propagation of light is quasi- 
instantaneous. NLO-active materials can play a central rôle in the ultrafast light encoding process. The magnitude of the relevant effects (mostly the electro-optic effect when based on quadratic NLO properties, but many effects for cubic NLO properties) is dependent on the NLO activity at a given wavelength (i.e. on the $\chi^{(2)}$ or $\chi^{(3)}$ coefficients of the material, which are themselves related to the molecular coefficients $\beta$ and $\gamma$ in equation 3) [1]. The switching of the NLO properties at a given wavelength (i.e. modification of the $\chi^{(2)}$ or $\chi^{(3)}$ coefficients) opens a new dimension in the encoding process. Per se, this switching process does not need to be rapid, although such a feature might be desirable if the NLO switching is performed using molecules, because the kinetic stability of the different "states" involved in the switching process are a crucial factor; indeed, the lifetime of the less stable state will influence the reversibility of the switching process, and therefore its "fatigue resistance". Thus, the faster the switching that can performed by a given stimulus, the better it might be for possible applications involving molecules.

Molecule-based switching of NLO properties has been discussed previously by Coe and others [60-62], and more specifically in the case of alkynyl NLO-phores by some of us quite recently [9]. Several stimuli have been employed thus far to switch the NLO properties of alkynyl complexes: (i) redox chemistry (to reversibly oxidize/reduce a metal alkynyl site), (ii) protonation (to form the corresponding vinylidene complex(es)), and most recently (iii) light (to trigger a conformational change in a photo-isomerizable unit appended to the alkynyl ligand). It is not the purpose of this section to discuss thoroughly these processes; rather, we will focus on the most important outcomes (largely related to redox switching) and on new developments. 


\subsection{Switching of quadratic NLO properties}

Redox switching of the quadratic NLO properties of iron alkynyl complexes has been reported ex situ (Table 9) [17,63], facilitated by the fact that dipolar or octupolar iron alkynyl complexes such as 67a-e and 68-70 (Figure 18) may afford chemically isolable Fe(III) forms. In contrast, in situ switching has been little exploited, a significant difficulty being the integration of the electrochemical cell with the HRS experiment. This is a serious limitation for molecule-based redox switchable materials, as we shall see below.

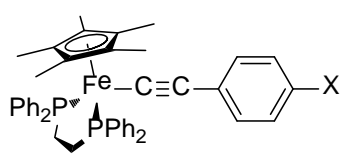

$67 a^{-e}$

$\left(\mathrm{X}=\mathrm{NO}_{2}, \mathrm{CN} \cdot \mathrm{H}^{\prime} \mathrm{OMe}^{\prime} \mathrm{NH}_{2}\right)$

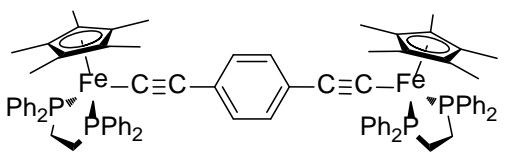

68

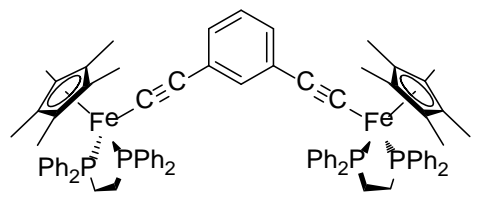

69

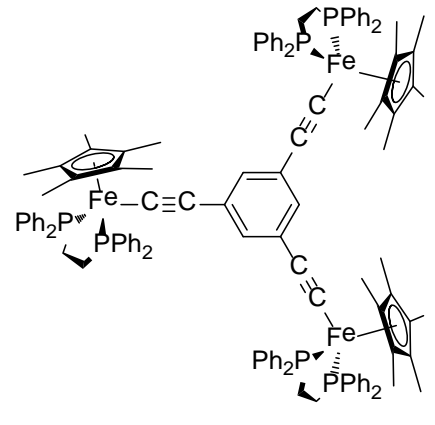

70

Figure 18. Mono- and trinuclear complexes 67a-e and 68-70.

\begin{tabular}{ccccc}
\hline & \multicolumn{4}{c}{$\boldsymbol{\beta}\left(10^{-30}\right.$ esu $)$} \\
\cline { 2 - 5 } complex & neutral & $\mathbf{1}^{+}$ & $\mathbf{2}^{+}$ & $\mathbf{3}^{+}$ \\
\hline $\mathbf{6 7 c}$ & 52 & 80 & $/$ & $/$ \\
$\mathbf{6 8}$ & 180 & 400 & 200 & $/$ \\
$\mathbf{6 9}$ & 210 & 150 & 200 & $/$ \\
$\mathbf{7 0}$ & 175 & 190 & 170 & 53 \\
\hline Table 9. & & &
\end{tabular}

\subsection{Switching of cubic NLO properties}


The possibility of controlling optical nonlinearity by reversible structural or electronic modifications at the molecular level ("molecular NLO switches”) has been of considerable interest over the past decade; this is particularly the case for cubic nonlinearity with Group 8 metal alkynyl complexes. The perturbation theory-derived relationship between cubic hyperpolarizability and linear optical transitions affords an insight into materials design to achieve molecular NLO switches (equation 6):

$$
\gamma \propto-\mu_{\mathrm{ge}}{ }^{4} / \mathrm{Ege}^{3}+\mu_{\mathrm{ge}}{ }^{2} \mu_{\mathrm{ee}}{ }^{2} / \mathrm{Ege}_{\mathrm{ge}}{ }^{2} \mathrm{Ege}_{\mathrm{ge}}+\mu_{\mathrm{ge}}{ }^{2}\left(\mu_{\mathrm{ee}}-\mu_{\mathrm{gg}}\right)^{2} / \mathrm{Ege}^{3}(\mathbf{6})
$$

where $\mu_{\mathrm{gg}}$ is the ground state dipole moment, $\mu_{\mathrm{ee}}$ is an excited state dipole moment, $\mu_{\mathrm{ee}}$ and $\mu_{\mathrm{ge}}$ are transition dipole moments, and $E_{g e}$ and $E_{g e}$ are optical absorption energies. This dependence of the molecular cubic NLO parameter on the energies of transitions and their transition dipole moments suggests that a reversible modification of a molecule that changes its optical absorption spectrum (wavelengths of maxima, extinction coefficients/oscillator strengths of charge-transfer bands) may also strongly modify its cubic NLO properties.

Group 8 metal alkynyl complexes often exhibit reversible redox processes, so redox-facilitated NLO switching has been a focus since the first report of this being accomplished in situ with 29 and trans- $\left[\mathrm{Ru}(\mathrm{C} \equiv \mathrm{CR}) \mathrm{Cl}\left(\mathrm{L}_{2}\right)_{2}\right] \mathbf{( 7 1}: \mathrm{R}=\mathrm{Ph}, \mathrm{L}_{2}=\mathrm{dppm}, \mathbf{7 2}: \mathrm{R}=\mathrm{C}_{6} \mathrm{H}_{4}-4-\mathrm{C} \equiv \mathrm{CPh}, \mathrm{L}_{2}=\mathrm{dppe}$; Figure 19) using a modified optically transparent thin-layer electrochemical (OTTLE) cell [34,64-66]. 

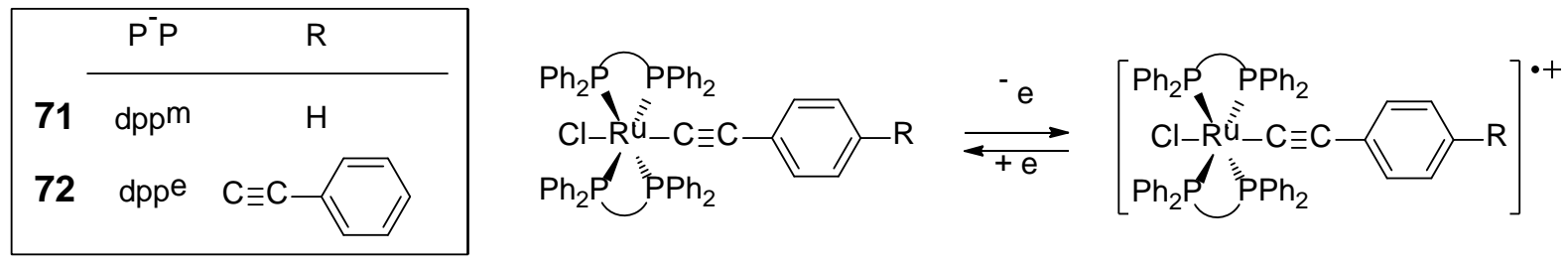

Figure 19. Redox interconversions performed in situ in an OTTLE cell with 71 and 72.

Across this series of complexes, the optical behaviour is similar (Table 10): UV-vis spectra of the neutral $\mathrm{Ru}^{\mathrm{II}}$ complexes possess absorption bands between 300 and $450 \mathrm{~nm}$ (assigned to MLCT transitions), and are optically transparent above $500 \mathrm{~nm}$. In their $\mathrm{Ru}^{\mathrm{III}}$ states, the oxidized complexes have a strong NIR absorption at $c a .800 \mathrm{~nm}$. The complexes were examined by Zscan measurements at $800 \mathrm{~nm}$ in both oxidation states. The nonlinearity of trans$\left[\mathrm{Ru}(\mathrm{C} \equiv \mathrm{CPh}) \mathrm{Cl}\left(\kappa^{2}-\mathrm{dppm}\right)_{2}\right]$ (71) proved too low to be measured at $800 \mathrm{~nm}$, but trans$\left[\mathrm{Ru}\left(\mathrm{C} \equiv \mathrm{CC}_{6} \mathrm{H}_{4}-4-\mathrm{C} \equiv \mathrm{CPh}\right) \mathrm{Cl}\left(\kappa^{2} \text {-dppe }\right)_{2}\right](72)$ and 29 are strong two-photon absorbers in their neutral state. Once oxidized, the NIR one-photon absorption of the complexes is "switched on" at around $800 \mathrm{~nm}$ and a saturable absorption effect for trans- $\left[\mathrm{Ru}(\mathrm{C} \equiv \mathrm{CPh}) \mathrm{Cl}\left(\kappa^{2}-\mathrm{dppm}\right)_{2}\right]^{+}\left(\mathbf{7 1}^{+}\right)$, trans- $\left[\mathrm{Ru}\left(\mathrm{C} \equiv \mathrm{CC}_{6} \mathrm{H}_{4}-4-\mathrm{C} \equiv \mathrm{CPh}\right) \mathrm{Cl}\left(\kappa^{2}-\mathrm{dppe}\right)_{2}\right]^{+}\left(\mathbf{7 2}^{+}\right)$and $\mathbf{2 8}^{3+}$ is possible, as reflected in their negative $\gamma_{\text {imag values. }}$ 


\begin{tabular}{|c|c|c|c|c|c|c|}
\hline Complex & $\begin{array}{l}\lambda_{\max } \\
(\mathbf{n m})\end{array}$ & $\begin{array}{c}\varepsilon \\
\left(10^{4} \mathrm{M}^{-1} \mathrm{~cm}^{-1}\right)\end{array}$ & $\begin{array}{c}\gamma_{\text {real }} \\
\left(10^{-36} \text { esu }\right)\end{array}$ & $\begin{array}{c}\gamma_{\text {imag }} \\
\left(10^{-36} \text { esu) }\right.\end{array}$ & $\begin{array}{c}|\gamma| \\
\left(10^{-36} \text { esu }\right)\end{array}$ & $\begin{array}{c}\sigma_{2} \\
(\mathbf{G M})\end{array}$ \\
\hline trans $-\left[\mathrm{Ru}(\mathrm{C} \equiv \mathrm{CPh}) \mathrm{Cl}\left(\kappa^{2}-\mathrm{dppm}\right)_{2}\right](\mathbf{7 1})$ & 318 & 1.0 & $<300$ & $<200$ & $=0$ & $=0$ \\
\hline trans- $\left[\mathrm{Ru}(\mathrm{C} \equiv \mathrm{CPh}) \mathrm{Cl}\left(\kappa^{2}-\mathrm{dppm}\right)_{2}\right]^{+}\left(\mathbf{7 1}^{+}\right)$ & 833 & 2.3 & $1300 \pm 500$ & $-2200 \pm 1000$ & $2600 \pm 1000$ & $-540 \pm 200$ \\
\hline trans- $\left[\mathrm{Ru}\left(\mathrm{C} \equiv \mathrm{CC}_{6} \mathrm{H}_{4}-4-\mathrm{C} \equiv \mathrm{CPh}\right) \mathrm{Cl}\left(\kappa^{2}-\mathrm{dppe}\right)_{2}\right](72)$ & 387 & 2.0 & $-100 \pm 100$ & $450 \pm 200$ & $460 \pm 200$ & $110 \pm 50$ \\
\hline trans $-\left[\mathrm{Ru}\left(\mathrm{C} \equiv \mathrm{CC}_{6} \mathrm{H}_{4}-4-\mathrm{C} \equiv \mathrm{CPh}\right) \mathrm{Cl}\left(\kappa^{2}-\mathrm{dppe}\right)_{2}\right]^{+}\left(72^{+}\right)$ & 893 & 3.6 & $2900 \pm 1000$ & $-1200 \pm 600$ & $3100 \pm 1000$ & $-300 \pm 70$ \\
\hline 29 & 413 & 7.8 & $-330 \pm 100$ & $2200 \pm 500$ & $2200 \pm 1000$ & $530 \pm 120$ \\
\hline $29^{3+}$ & 893 & 20.1 & $13500 \pm 3000$ & $-4700 \pm 500$ & $14000 \pm 3000$ & $-1200 \pm 100$ \\
\hline
\end{tabular}

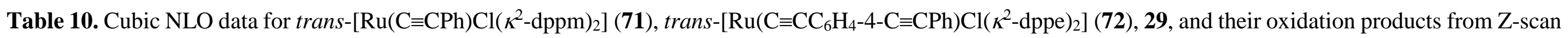
studies at $800 \mathrm{~nm}[34,64-66]$. 
The third-order NLO behavior of the $\mathrm{Fe}\left(\kappa^{2}-\mathrm{dppe}\right)\left(\eta^{5}-\mathrm{C}_{5} \mathrm{Me}_{5}\right)$ analogue (73; Figure 20) of the trans-[RuCl( $\kappa^{2}$-dppe $)_{2}$ ] complex 29 was also investigated by Z-scan [67]. A $695 \mathrm{~nm}$ laser beam was used because the organoiron complex is optically transparent in its two redox forms at this wavelength. Similar to its organoruthenium counterpart, the neutral complex is a twophoton absorber and, once oxidized, it becomes a saturable absorber.

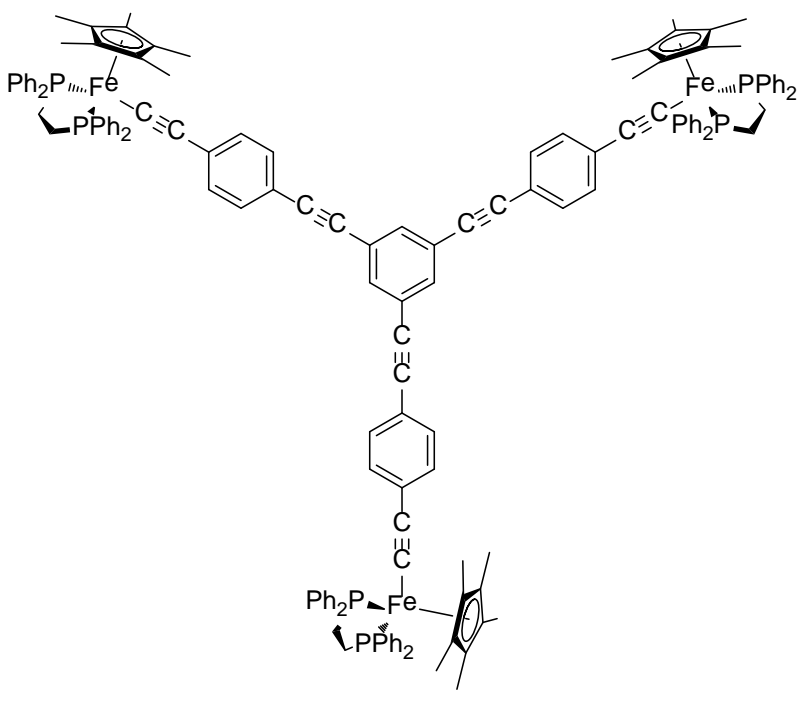

73
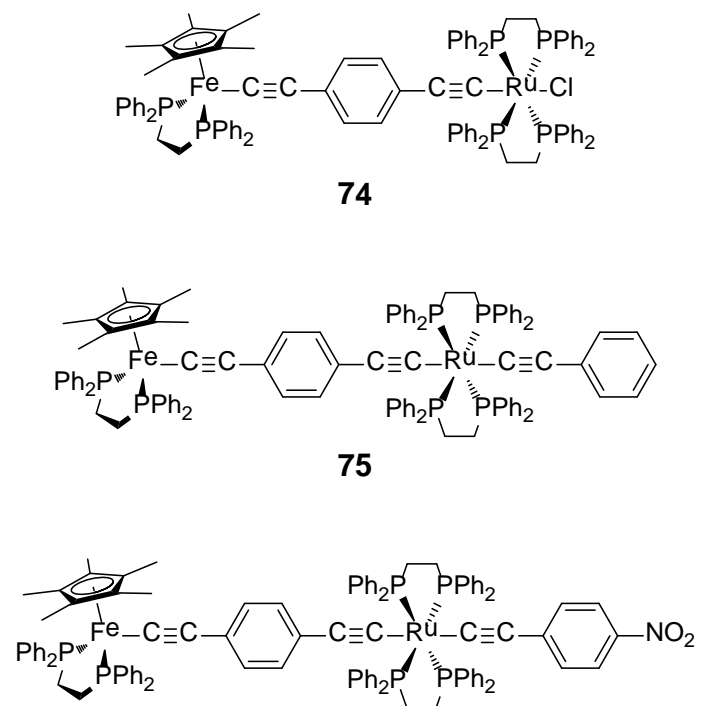

76

Figure 20. Complexes 72-76.

The above mentioned iron and ruthenium units are oxidized at very different potentials $(\mathrm{Fe} \approx$ -0.20 V vs SCE; Ru 0.40 - 0.50 V vs SCE), so were combined to afford complexes 74-76 (Figure 20) with three accessible oxidation states (corresponding formally to $\mathrm{Fe}^{\mathrm{II}} \mathrm{Ru}^{\mathrm{II}}$, $\mathrm{Fe}^{\mathrm{III}} \mathrm{Ru}^{\mathrm{II}}$, and $\left.\mathrm{Fe}^{\mathrm{III}} \mathrm{Ru}^{\mathrm{III}}\right)$. Redox switching between these three states can be performed in situ in the OTTLE cell. It was also established that because of the significant electronic coupling between the two redox sites, the mixed-valent monocation $\left(\mathbf{M V}-\mathbf{A}^{+}\right)$of any of these redox families could not be (photochemically) switched to its redox isomer (MV-B $\mathbf{B}^{+}$) by irradiation 
in the intervalence charge transfer (IVCT) band (Figure 21) [68]; such a possibility would have provided access to an additional state by a different (orthogonal) stimulus.

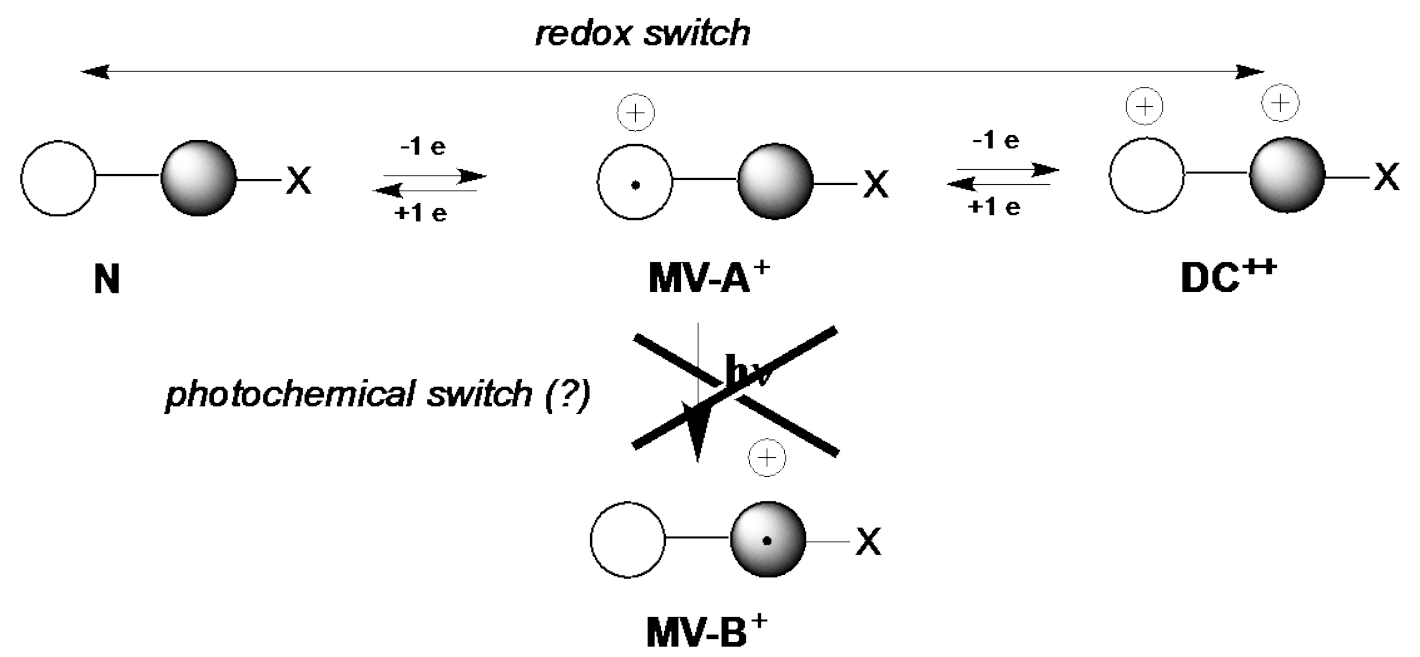

Figure 21. Possible interconversions between four states for the complexes 74-76.

The third-order NLO activities of $\mathbf{7 4 ~ - ~} \mathbf{7 6}$ in their neutral and oxidized forms were determined by Z-scan (Table 11) [68]. Complex 74 has negligible activity at $790 \mathrm{~nm}$ (the absorption maximum of the di-oxidized complex $\mathbf{7 4}^{2+}$, and a wavelength at which both $\mathbf{7 4}$ and $\mathbf{7 4}^{++}$are transparent). After oxidation of the organoiron moiety, the complex cation $\mathbf{7 4}^{+}$is a two-photon absorber (positive $\gamma_{\text {imag). }}$ Further oxidation of the organoruthenium unit "switches on" the linear absorption of the complex dication $\mathbf{7 4}^{2+}$, which behaves as a saturable absorber

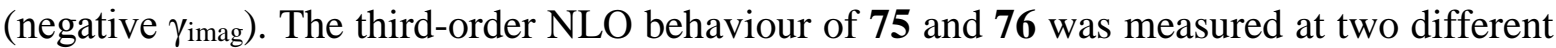
wavelengths: 750 and $1250 \mathrm{~nm}$. At $750 \mathrm{~nm}, 75$ and 76 have no linear absorption in their neutral and first oxidized state but are absorptive in their di-oxidized $\mathrm{Fe}^{\mathrm{III}} \mathrm{Ru}^{\mathrm{III}}$ form $\left(7^{2+} / 7^{2+}\right)$. Only the $\mathrm{Fe}^{\mathrm{III}} \mathrm{Ru}^{\mathrm{II}}$ and $\mathrm{Fe}{ }^{\mathrm{III}} \mathrm{Ru}^{\mathrm{III}}$ complexes $\left(\mathbf{7 5}^{+} / \mathbf{7 6}^{+}\right.$and $\left.\mathbf{7 5}^{2+} / \mathbf{7 6}^{2+}\right)$ are absorptive at $1250 \mathrm{~nm}$, with the di-oxidized forms more absorptive than the mono-oxidized ones.

In contrast to 74, the neutral complexes 75/76 are two-photon absorbers at both wavelengths. The difference in the linear optical behaviour of the $\mathrm{Fe}^{\mathrm{III}} \mathrm{Ru}^{\mathrm{II}}$ complexes $\mathbf{7 5}^{+} / \mathbf{7 6}^{+}$between the 
two wavelengths translates into a difference in their nonlinear activity. At $750 \mathrm{~nm}$ they are two-photon absorbers with an increased intensity of the response compared to their neutral forms. Oxidation of the organoiron synthon gives rise to NIR one-photon absorption bands and leads to saturable absorber behaviour at $1250 \mathrm{~nm}$. However, in their $\mathrm{Fe}^{\mathrm{III}} \mathrm{Ru}{ }^{\mathrm{III}}$ state, $\mathbf{7 5}^{2+}$ and $\mathbf{7 6}^{2+}$ are saturable absorbers at both wavelengths, due to the presence of visible and NIR absorption bands. An octupolar example of 75 (77; Figure 22) has been prepared and the NLO properties of this hexanuclear heterobimetallic assembly has been examined across the accessible oxidation states, with similar results.

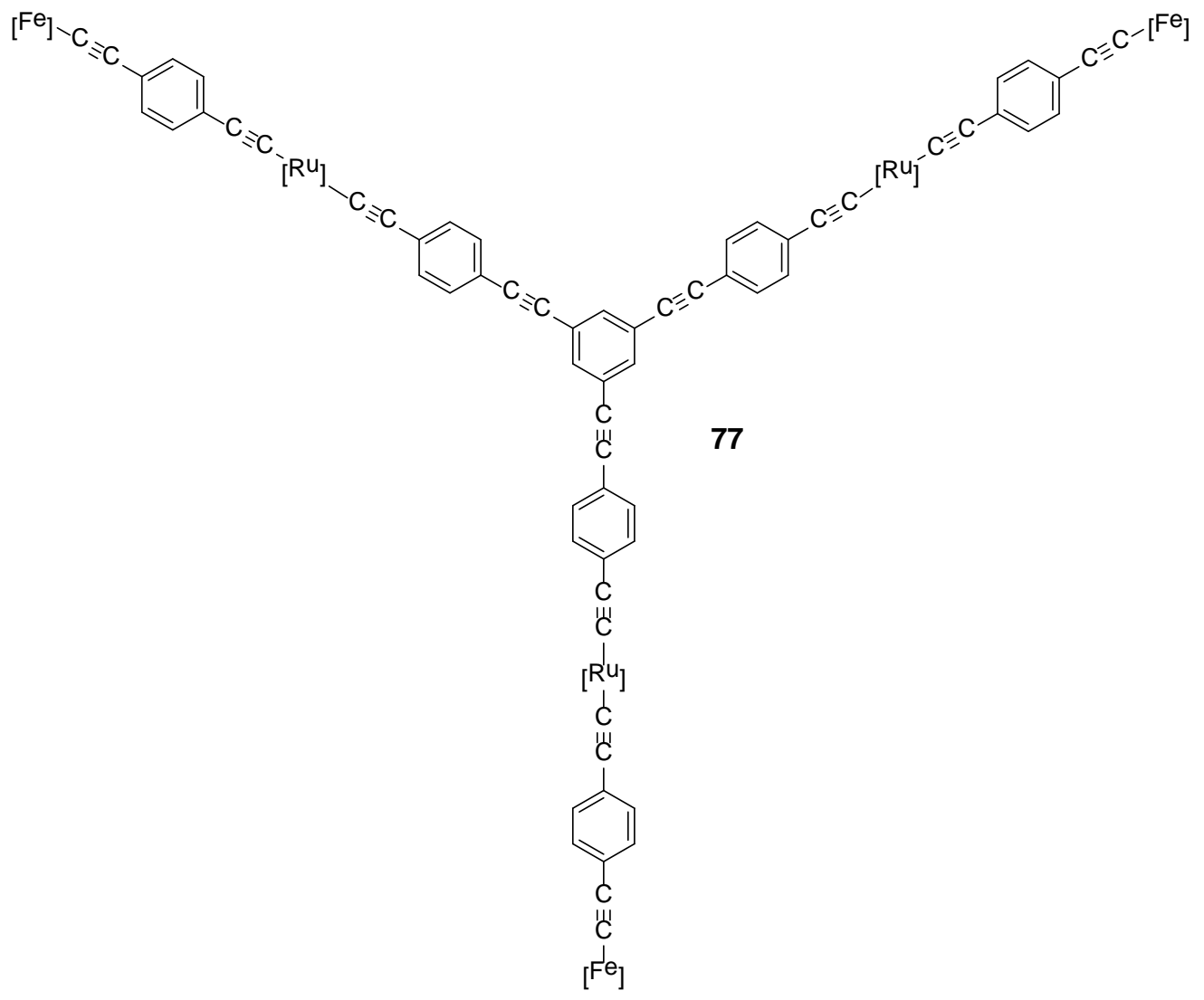

Figure 22. Octupolar complex $77\left([\mathrm{Fe}]=\mathrm{Fe}\left(\kappa^{2}-\mathrm{dppe}\right)\left(\eta^{5}-\mathrm{C}_{5} \mathrm{Me}_{5}\right) ;[\mathrm{Ru}]=\operatorname{trans}-\left[\mathrm{Ru}\left(\kappa^{2}-\right.\right.\right.$ dppe) $\left.)_{2}\right]$.

\begin{tabular}{ccccc}
\hline Complex & $\gamma_{\text {real }}$ & $\gamma_{\text {imag }}$ & $|\gamma|$ & $\sigma_{2}$ \\
& $\left(1^{-36} \mathrm{esu}\right)$ & $\left(\mathbf{1 0}^{-36} \mathrm{esu}\right)$ & $\left(\mathbf{1 0}^{-36} \mathrm{esu}\right)$ & $(\mathrm{GM})$ \\
\hline
\end{tabular}




\begin{tabular}{|c|c|c|c|c|}
\hline \multicolumn{5}{|c|}{$790 \mathrm{~nm}$} \\
\hline 74 & $<100$ & $<100$ & 0 & 0 \\
\hline $74^{+}$ & $-450 \pm 100$ & $1600 \pm 200$ & $1600 \pm 250$ & $420 \pm 50$ \\
\hline $74^{2+}$ & $<300$ & $-970 \pm 200$ & $1000 \pm 300$ & $-250 \pm 50$ \\
\hline \multicolumn{5}{|c|}{$750 \mathrm{~nm}$} \\
\hline 75 & $-3700 \pm 800$ & $1900 \pm 400$ & $4200 \pm 1000$ & $710 \pm 150$ \\
\hline $75^{+}$ & nd & $3300 \pm 700$ & & $1200 \pm 250$ \\
\hline $75^{2+}$ & nd & $-700 \pm 150$ & & $-260 \pm 50$ \\
\hline 76 & $-600 \pm 100$ & $3900 \pm 800$ & $4000 \pm 800$ & $1400 \pm 300$ \\
\hline $76^{+}$ & nd & $5900 \pm 1000$ & & $2200 \pm 400$ \\
\hline $76^{2+}$ & nd & $-3600 \pm 800$ & & $-1300 \pm 300$ \\
\hline 77 & $-30000 \pm 6000$ & $26000 \pm 5000$ & $40000 \pm 8000$ & $9500 \pm 2000$ \\
\hline $77^{3+}$ & - & $17000 \pm 3400$ & & $6200 \pm 1200$ \\
\hline $77^{6+}$ & - & $-80000 \pm 16000$ & & $-29000 \pm 40000$ \\
\hline
\end{tabular}

Table 11. Experimental cubic nonlinear optical response parameters of $\mathbf{7 4}$ - $\mathbf{7 7}$ across their accessible redox states at 790 or $750 \mathrm{~nm}$ in $\mathrm{CH}_{2} \mathrm{Cl}_{2}$ [68].

Two mutually independent (“orthogonal”) types of switching were employed with the cruciform complex $\mathbf{7 8}$ (protic and redox processes), affording three distinct states with different linear absorption properties (Figure 23). The UV-vis spectrum of $\mathbf{7 8}$ shows a significant absorption centered at $480 \mathrm{~nm}$ (MLCT band); the complex is transparent at longer wavelengths. This MLCT band disappears following protonation with $\mathrm{HBF}_{4}$, yielding the more transparent $\mathbf{7 8}-\mathrm{H}_{4}{ }^{4+}$, whereas oxidation of $\mathbf{7 8}$ to $\mathbf{7 8}^{4+}$ results in the appearance of a strong LMCT band at ca. $900 \mathrm{~nm}$. The third-order nonlinearities of $\mathbf{7 8}, \mathbf{7 8 - \mathbf { H } _ { 4 }}{ }^{\mathbf{4}}$ and $\mathbf{7 8}^{\mathbf{4 +}}$ were measured by broad spectral range Z-scan, revealing that, at specific wavelengths, the behavior of the complex can be completely different between two forms; for example, oxidation of $\mathbf{7 8}$ to $\mathbf{7 8}^{4+}$ results in a change from two-photon absorption to saturable absorption at $750 \mathrm{~nm}$ [69]. 


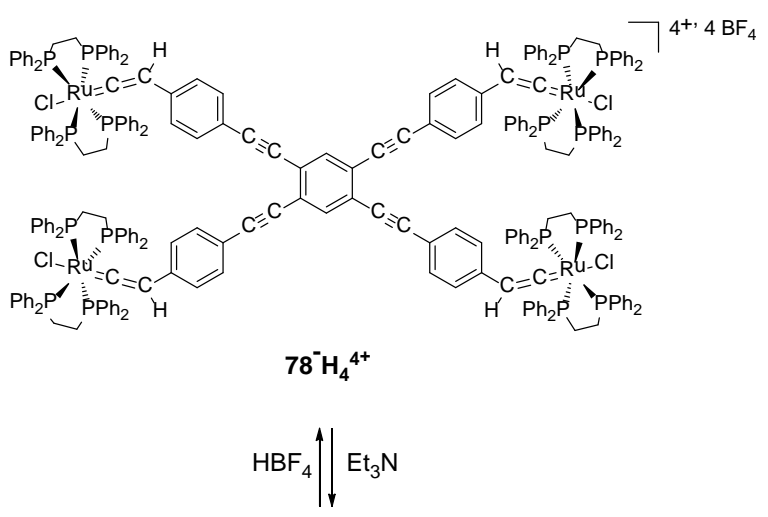

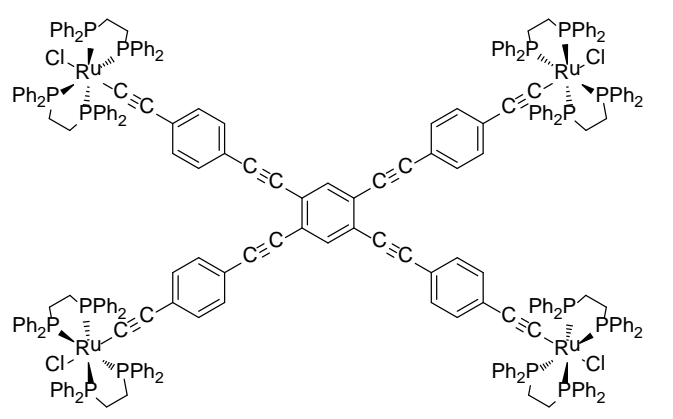

78

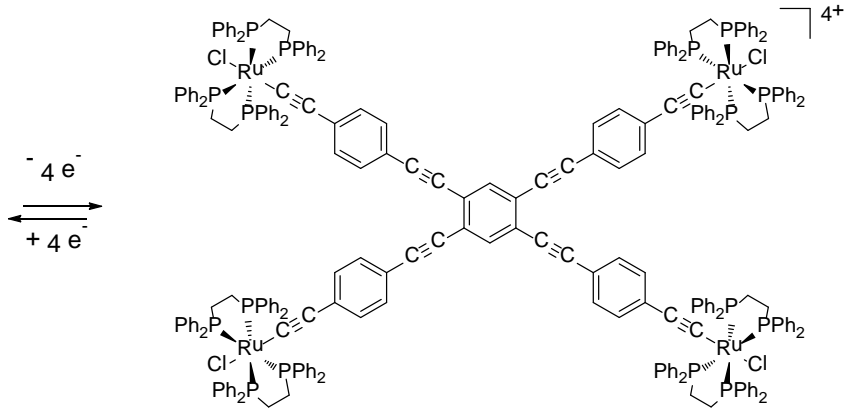

$78^{4^{+}}$

Figure 23. Complexes 78- $\mathbf{H}_{4}{ }^{4+}, \mathbf{7 8}$, and $\mathbf{7 8}^{4+}$.

NLO switching was taken a step further with the six-states complex 79 (Figure 24), addressable with three orthogonal stimuli [70]. Ruthenium phenylalkynyl units, employed in 78 to demonstrate NLO switching by redox and protic means, were assembled with a photochromic 5,5'-dithienylperfluorocyclopentene bridge (a DTE moiety). Photoisomerization of the DTE results in the "ON" and "OFF" switching of linear absorption in the visible range for the complex in its vinylidene, resting state alkynyl and oxidized alkynyl forms. A strong one-photon absorption band is present at around $650 \mathrm{~nm}$ in the spectra of the closed forms, but absent in the spectra of the open forms. The same variations, as previously described for the cruciform complex 78, are associated with the interconversion between the vinylidene and alkynyl complex forms: an MLCT band is present in the linear spectra of the alkynyl forms but absent for the vinylidene forms, while oxidation of the ruthenium center 
gives rise to a strong LMCT band for both open and closed forms of the complex. As expected, these variations in the linear spectra of the complex between its six states influence the nonlinear behavior (Figure 25). The nonlinear behavior of 79 can be switched over a larger wavelength range than the cruciform complex 78. As a result, switching between saturable absorber, two-photon absorber, and inactive forms is more effective. Moreover, when similar behavior occurs with two switchable states at a specific wavelength, the amplitude of the responses is often significantly different, facilitating discrimination of the states.

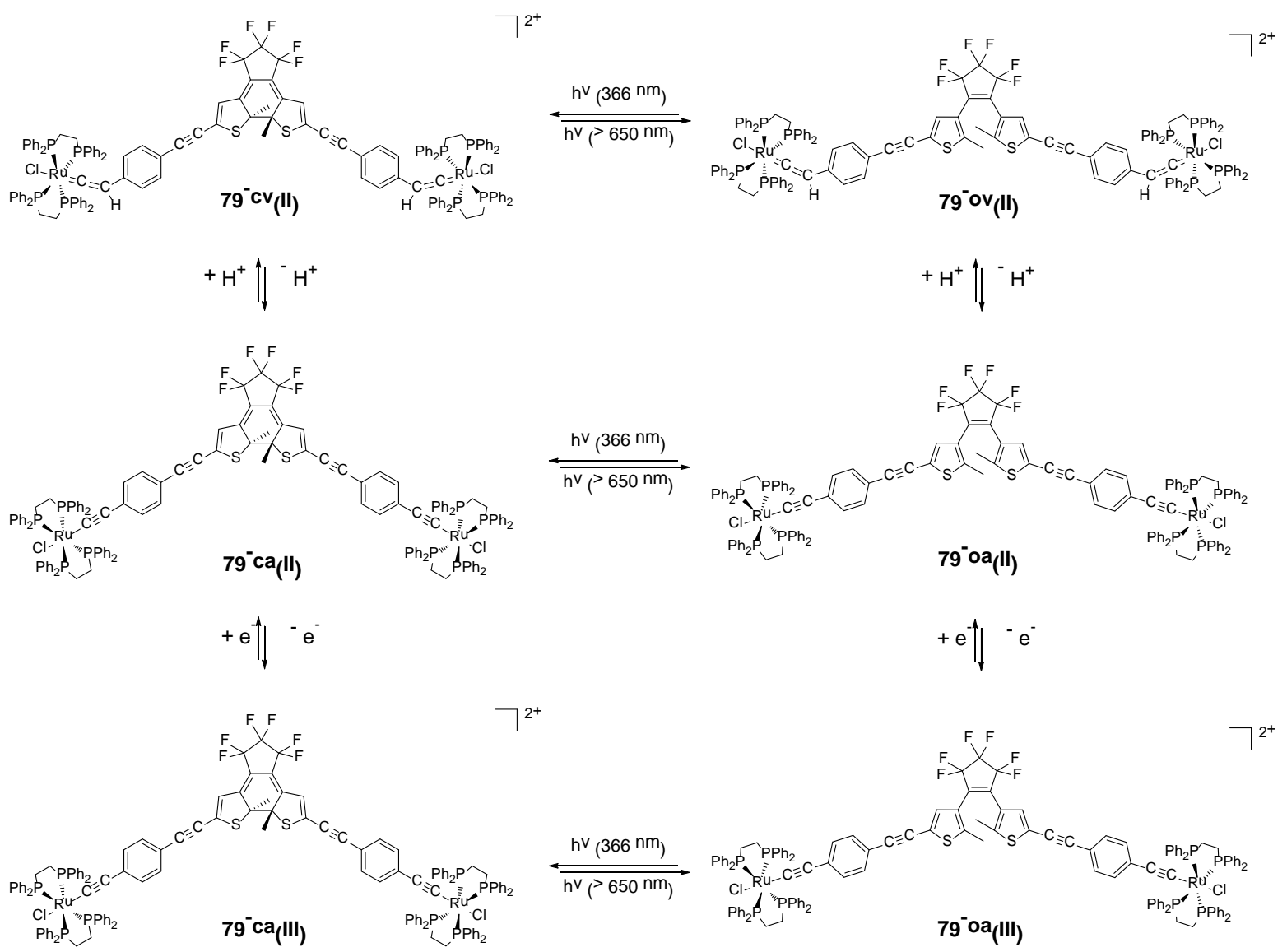

Figure 24. Complexes 79 (o = open, $\mathrm{c}=$ closed, $\mathrm{a}=$ alkynyl, $\mathrm{v}=$ vinylidene, (II/III): formal oxidation state of the metal centre). 


\begin{tabular}{|c|c|c|c|c|c|c|c|c|c|c|c|}
\hline & 500 & 600 & 700 & 800 & 900 & 1000 & 1100 & 1200 & \begin{tabular}{|l|l|}
1300 & 1400 \\
\end{tabular} & $\mid 1500$ & $\mid 1600$ \\
\hline ov(II) & & & & & & & & & & & \\
\hline $\operatorname{cv}($ II) & & & & & & & & & & & \\
\hline ca(II) & & & & & & & & & & & \\
\hline ca(III) & & & & & & & & & & & \\
\hline oa(III) & & & & & & & & & & & \\
\hline oa(II) & & & & & & & & & & & \\
\hline
\end{tabular}

Figure 25. Nonlinear behavior of $\mathbf{7 9}$ across its six states as a function of the laser irradiation wavelength (nm, horizontal scale). $\mathbf{o}=$ open form, $\mathbf{c}=$ closed form, $\mathbf{a}=$ alkynyl, $\mathbf{v}=$ vinylidene $(\mathrm{II} / \mathrm{III})=$ formal oxidation state of the metal centers. Red: saturable absorber, blue: nonlinear absorber, yellow: inactive nonlinear absorber, white $=$ no data reported [70].

\subsection{Towards switchable molecule-based materials with metal alkynyl complexes?}

Although (to the best of our knowledge) redox switchable quadratic NLO materials have not yet been used in any applications, redox-switchable cubic NLO materials have been proposed for several technological developments such as optronics computer cores [71]. The existing materials currently envisioned for such purposes are, however, solid-state and silicon-based in nature [72], and for which the cubic NLO properties are size-dependent, rendering miniaturization impossible beyond a certain limit. The downsizing limits are more remote with equivalent molecule-based materials, so from the applied point of view, there is a strong incentive to develop new molecule-based photonic materials.

\subsubsection{Materials for switching of quadratic properties}

As mentioned above, the requirement of having all the dipoles aligned for observable quadratic NLO properties limits the prospects for redox switchable materials. Very few 
attempts have been made, the first of which (to the best of our knowledge) being to deposit redox-active ferrocene-based dipolar compounds such as $\mathbf{8 0}$ (Figure 26) on a conducting (gold) surface and to then use it as a working electrode to switch the redox state of the donor group in the monolayer by electrochemical means [73]. However, in the switching process, the molecular response was (apparently) swamped by that of the underlying gold surface and by the redox-induced structural changes undergone by the monolayer. In a more recent approach [74], Langmuir-Blodgett monolayers of the dipolar complexes $\mathbf{8 1}$ were grown on a translucent ITO electrode. Molecule-based NLO redox switching was clearly demonstrated, but a loss of activity of the monolayer was evidenced upon cycling (above 3 times). Thus far, no analogous material has been isolated with alkynyl complexes.
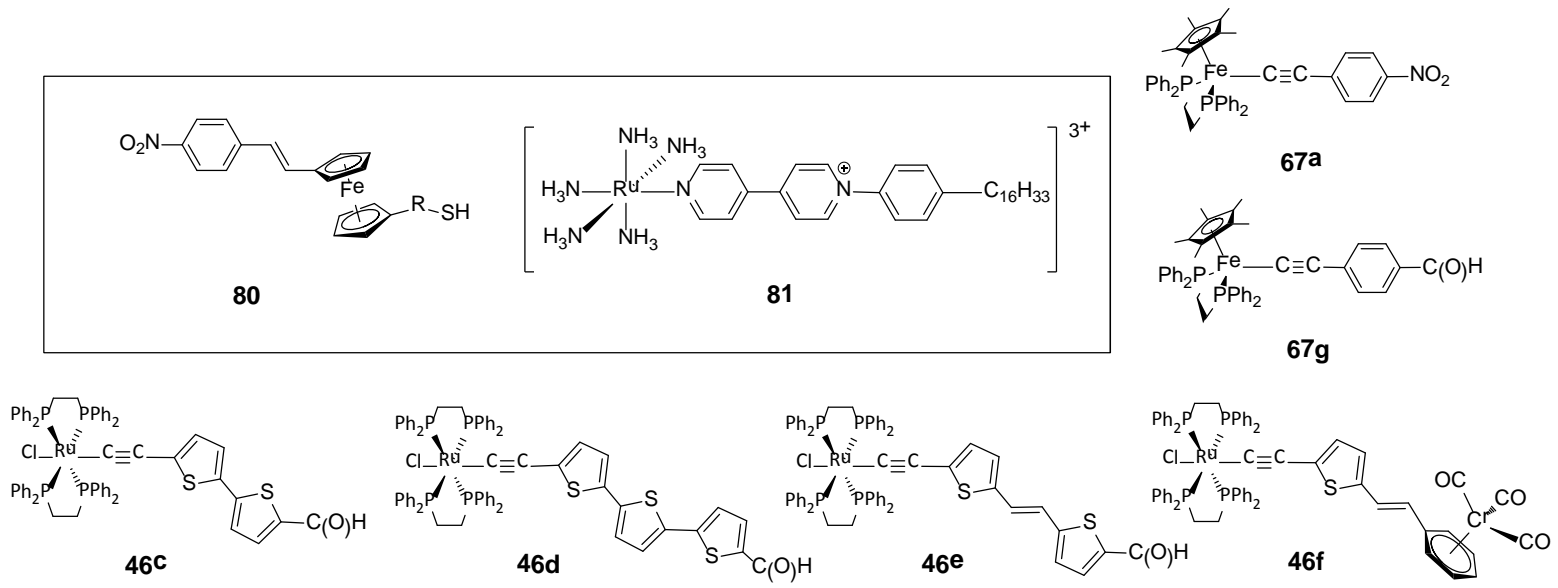

Figure 26. Complexes involved in SHG-active molecule-based materials.

Metal alkynyl complex-based materials for second harmonic generation (SHG) are scarce. In 2005, acoustically induced second-harmonic generation (AI-SHG) was reported for complexes 46c-f (Figure 26) incorporated (ca. 5-6\% w/w) in a poly(methylmethacrylate) (PMMA) host [75]. Materials exhibiting SHG values as large as $1.9 \mathrm{pm} / \mathrm{V}$ were obtained at $980 \mathrm{~nm}$ following optical poling, but the resulting $\chi^{(2)}$ value is not stable and decreases over 
time (by ca. 70 \%). AI-SHG values of $c a .0 .8 \mathrm{pm} / \mathrm{V}$ were obtained at $1760 \mathrm{~nm}$ with a doped polymer made from $46 \mathrm{c}$ in the presence of an acoustic signal (80 $\mathrm{Hz}$ to $1.1 \mathrm{MHz}$ ) [42]; the latter is required to obtain an SHG signal from these samples containing randomly oriented NLO-active complexes [76]. No clear relationship between the molecular properties of the constituent complexes and the SHG response of the resultant materials could be drawn. Oriented organometallic thin films were also obtained from 45a-c (Figure 28) by corona poling at $120^{\circ} \mathrm{C}$ over $5 \mathrm{~min}$, the best $\chi^{(2)}$ values of $c a .1 \mathrm{pm} / \mathrm{V}$ at $1064 \mathrm{~nm}$ being seen for $\mathbf{4 5 b}$ $[77,78]$. Stability of the compounds at $120^{\circ} \mathrm{C}$ is a problem limiting longer poling times. SHGactive oriented hybrid materials were also obtained from dipolar organoiron(II) NLO-phores such as $\mathrm{Fe}\left(\mathrm{C} \equiv \mathrm{C}-4-\mathrm{C}_{6} \mathrm{H}_{4} \mathrm{X}\right)\left(\kappa^{2}\right.$-dppe $)\left(\eta^{5}-\mathrm{C}_{5} \mathrm{Me}_{5}\right)\left(67 \mathbf{a}: \mathrm{X}=\mathrm{NO}_{2}\right.$, Figure $\left.27 ; \mathbf{6 7 g}: \mathrm{X}=\mathrm{C}(\mathrm{O}) \mathrm{H}\right)$ [79]. These new polymers were synthesized by photopolymerization of oligoether-acrylates (OEAs) containing the NLO-active complexes 67a and $67 \mathrm{~g}$ in the presence of an electrostatic dc field, and without heating. SHG values of $c a .3 \mathrm{pm} / \mathrm{V}$ at $1907 \mathrm{~nm}$ were measured with the samples containing $\mathbf{6 7 a}$, which also corresponds to the most active complex. However, there is room for improvement, since these values are roughly two orders of magnitude below these obtained by the most active all-organic poled polymers designed for HRS [80]. Moreover, due to the essentially insulating nature of PMMA and polyacrylate polymers, there is no possibility of switching the NLO activity of the alkynyl complexes embedded in the polymeric host by electrochemical means with these hybrid materials.

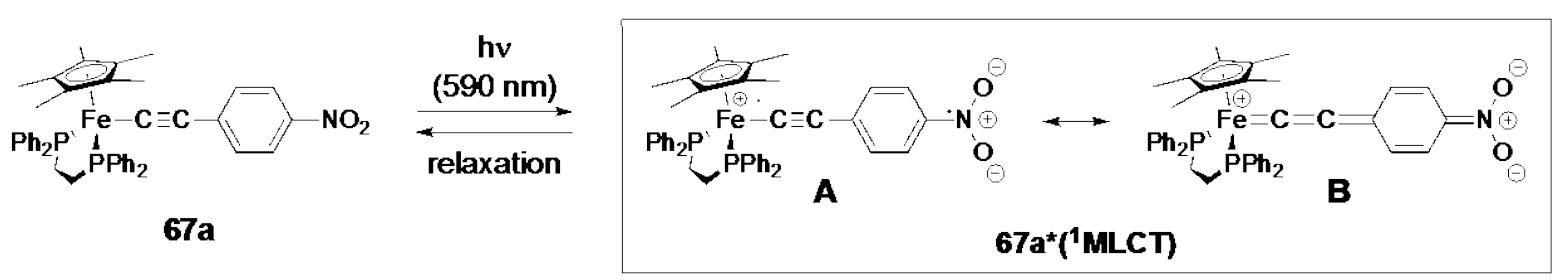

Figure 27. Photochemical switching with 67a. 
To perform modulation of the HRS signal with such hybrid materials, some of us have recently explored the possibility of photoswitching 67a by irradiating it in its metal-ligand charge transfer (MLCT) band (67a*(1MLCT)) at ca. $600 \mathrm{~nm}$, and monitored the decay of the resultant species by ultrafast time-resolved (fs) spectrocopy (Figure 27) [81]. According to its valence bond structure, the metal center bears a positive charge in $67 a^{*}\left({ }^{1} \mathbf{M L C T}\right)$ and certainly possesses a sizeable Fe(III) character (form A). It should therefore possess a diminished hyperpolarizability relative to the ground state (GS) 67a. The study reveals that the initially populated MLCT singlet state $\mathbf{6 7 a *}\left({ }^{1} \mathbf{M L C T}\right)$ decays into a longer-lived metastable triplet state within 15 ps, which eventually reverts back to the GS. This triplet state, which likewise to $\mathbf{6 6} \mathbf{a}^{*}\left({ }^{\mathbf{1}} \mathbf{M L C T}\right)$ should exhibit a strongly diminished hyperpolarizability, is formed with a very high quantum yield. This study indicates that control of the HRS output might indeed be performed by photochemistry with polymers incorporating 67a, but more work is clearly needed.

\subsubsection{Materials for switching of cubic NLO properties}

For cubic NLO properties it is not necessary to orient the constituent NLO-phores, since no symmetry requirements apply. Thus, the synthesis of molecular materials exhibiting such properties from ad hoc molecules is considerably easier than those of SHG-active materials. As a result, quasi-infinite metal-alkynyl polymers such as those shown in Figure 28 (82a-b, for various values of m, p and n) [82] have been thoroughly investigated for their cubic NLO properties since the late 1980s [83-86]. Related materials made from discrete metal alkynyl complexes are scarce. $\chi^{(3)}$ values (of $c a .20 \times 10^{-13}$ esu) were obtained from third-harmonic generation measurements (THG) for doped polymers similar to those described above but 
instead incorporating organoruthenium complexes 45a-c (Figure 28) $[87,88]$. The largest value $\left(3.0 \times 10^{-20} \mathrm{~m}^{2} / \mathrm{V}^{2}\right.$ or $\left.21.5 \times 10^{-13} \mathrm{esu}\right)$ was found for $\mathbf{4 5 b}$ using the model of Kajzar and Messier [89,90]. All-optical switching (based on the Kerr effect) was recently reported with these films incorporating the azo-containing complexes 45a-c [91], and the thermal behavior of these films has been investigated [92], while similar hybrid materials incorporating NLOphores 45a-f (Figure 28) have been investigated for optical date storage applications [93-96].

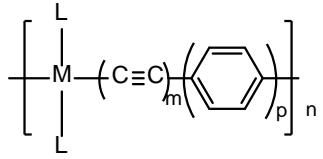

$81 a^{\top} b$ $\left(M=P d^{\prime} P t ; L=P^{\prime} h_{3}\right)$

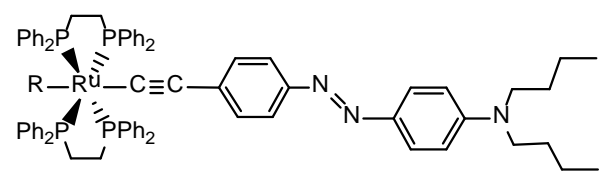

$45 a^{-} f$
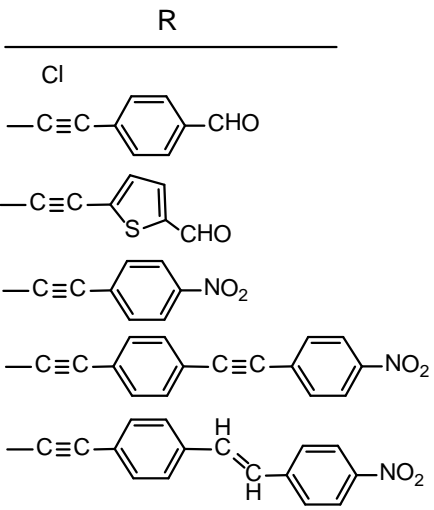

Figure 28. Examples of metal alkynyl polymers and doped polymers for which cubic NLO measurements have been undertaken.

To access redox-switchable surface-supported NLO-phores, which are desirable but still challenging targets, an approach similar to that pursued with $\mathbf{8 0}$ has been explored, i.e. by grafting NLO-active alkynyl complexes with a pendant terminal alkyne unit onto $p$-doped SiH surfaces. Because $p$-doped silicon is a semiconductor, the functionalized silicon chip might additionally be used as a working electrode to control the redox state of the NLO-active monolayer. 

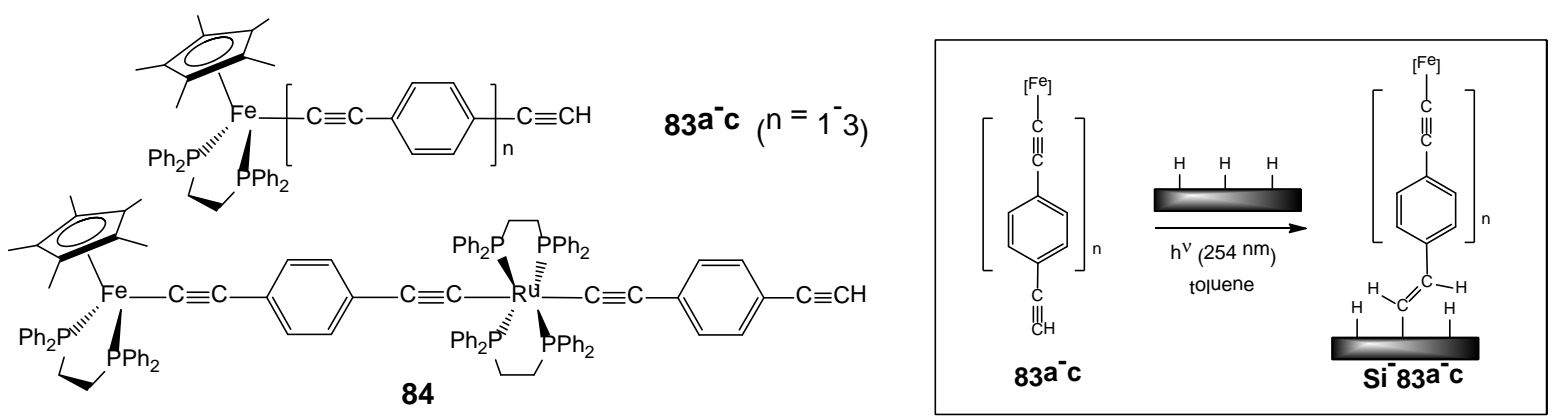

Figure 29. Complexes 83a-c and 84 and photochemical grafting of 83a-c onto Si-H.

Photochemical functionalization of hydrogenated silicon ( $\mathrm{Si}-\mathrm{H})$ surfaces by 83a-c forms densely packed redox-active monolayers (Figure 29) [97]. The linker-dependent apparent rate constants ( $\left.k_{\mathrm{app}}\right)$ derived for the electron-exchange rates between the terminal Fe(II) centers and the underlying silicon interface are amongst the highest obtained for organometallic monolayers $\left(k_{\mathrm{app}}>350 \mathrm{~s}^{-1}\right)$ on this type of support [98], evidencing that much faster rates might be obtained than previously reported for redox switching in Langmuir-Blodget films (which necessitated a switching cycle of ca. 2 min) [99]. Furthermore, the 4ethynylphenylethynyl analogue (84; Figure 29) of 75 (Figure 20) has been attached to a hydrogenated silicon surface to form densely packed monolayers (around $10^{-10} \mathrm{~mol} \mathrm{~cm}^{-2}$ ) and cycled through its three oxidation states [97], with similar behavior to that seen in solution; again, redox switching can be performed with high speeds for both redox systems addressed $\left(k_{\mathrm{app}}>200 \mathrm{~s}^{-1}\right)$ [100]. While the surface coverage at present may not permit measurement of the monolayer cubic NLO properties (because of insufficient molecular number density), transfering this silicon surface-based chemistry to the bulk (using $p$-doped porous $\mathrm{Si}-\mathrm{H}$ ) might afford access to Si-supported nanostructured materials that may have applications possibilities for controlling optical nonlinearity under potential control in their transparency window.

\section{Conclusion}


Studies over the previous decade have demonstrated that Group 8 metal alkynyl complexes can be engineered to possess large nonlinearities, which various scaling procedures have suggested are arguably superior to similar, purely organic, compounds. Dipolar complexes are very efficient as quadratic NLO materials, but quadrupolar and octupolar complexes have demonstrable potential with specific cubic NLO properties and, for the latter, nonlinearity can be increased on dendrimer generation increase without loss of transparency. Examples with large values of multi-photon absorption cross-sections are of particular interest for possible applications necessitating tight control of the interaction volume (multi-photon microscopy, micro-machining, etc.). Molecular switching of the nonlinear optical activities has been demonstrated with metal alkynyl complexes employing multiple orthogonal stimuli $(\mathrm{pH}$, voltage, light) to generate molecules that are of interest in molecular logic applications.

These achievements have thus far been largely restricted to solution studies. Translating this solution behavior to the solid-state is a necessary goal for many possible applications. Albeit challenging, the task of isolating metal alkynyl-based materials allowing the remote control of their quadratic or cubic hyperpolarizabilities by light or electrochemistry is clearly not out

of reach, but will necessitate further work. In this respect, the recent demonstration of reversible redox behavior for surface-supported heterobimetallic iron-ruthenium assemblies appears quite promising in progressing towards these stimulating objectives, both from fundamental and applied perspectives.

\section{Acknowledgements}

G.G. thanks the Region Bretagne for partial funding of a Ph.D. stipend, M.P.C. thanks the 
Australian Research Council (ARC) for an Australian Research Fellowship and M.G.H. thanks the ARC for an Australian Professorial Fellowship. M.G.H., F.P., and M.P.C. would like to thank the academic collaborators and all the students that contributed to these studies, and the ARC, the Region Bretagne, the CNRS (PICS Program $N^{\circ} 5676$ ), the French Embassy in Australia (travel support to G.G.), and the Agence Nationale de la Recherche (ANR 09BLAN-0109 Grant) for financial support.

\section{References}

[1] C.E. Powell, M.G. Humphrey, Coord. Chem. Rev. 248 (2004) 725.

[2] B.J. Coe, in Comprehensive Coordination Chemistry II, J.A. McCleverty, T.J. Meyer, Eds, Elsevier: Oxford, 2004; Vol. 9, pp 621-687.

[3] M.E. Thompson, P.E. Djurovich, S. Barlow, S.R. Marder, in Comprehensive Organometallic Chemistry III, R.H. Crabtree, D.M.P. Mingos, Eds, Elsevier: Oxford, 2007; Vol. 12, pp 101-194.

[4] J.P. Morrall, G.T. Dalton, M.G. Humphrey, M. Samoc, Adv. Organomet. Chem. 55 (2008) 61.

[5] B.J. Coe, N.R.M. Curati, Comments Inorg. Chem. 25 (2004) 147.

[6] S. di Bella, C. Dragonetti, M. Pizzotti, D. Roberto, F. Tessore, R. Ugo, in Topics in Organometallic Chemistry, H. Le Bozec, V. Guerchais, Eds, Springer-Verlag: Berlin, 2010; Vol. 28, pp 1-55.

[7] M.G. Humphrey, M.P. Cifuentes, M. Samoc, in Topics in Organometallic Chemistry, H. Le Bozec, V. Guerchais, Eds, Springer-Verlag: Berlin, 2010; Vol. 28, pp 57-73.

[8] C. Andraud, O. Maury, Eur. J. Inorg. Chem. (2009) 4357. 
[9] K.A. Green, M.P. Cifuentes, M. Samoc, M.G. Humphrey, Coord. Chem. Rev. 255 (2011) 2530.

[10] J.L. Oudar, D. Chemla, J. Chem. Phys. 66 (1977) 1626.

[11] S.R. Marder, D.N. Beratan, L.T. Cheng, Science 252 (1991) 103.

[12] S.R. Marder, C.B. Gorman, B.G. Tiemann, L.T. Cheng, J. Am. Chem. Soc. 115 (1993) 3006.

[13] J. Zyss, I. Ledoux, Chem. Rev. 94 (1994) 77.

[14] P.A. Humphrey, P. Turner, A.F. Masters, L.D. Field, M.P. Cifuentes, M.G. Humphrey, I. Asselberghs, A. Persoons, M. Samoc, B. Luther-Davies, Inorg. Chim. Acta 358 (2005) 1663.

[15] C.E. Powell, M.P. Cifuentes, A.M. McDonagh, S.K. Hurst, N.T. Lucas, C.D. Delfs, R. Stranger, M.G. Humphrey, S. Houbrechts, I. Asselberghs, A. Persoons, D.C.R. Hockless, Inorg. Chim. Acta 352 (2003) 9.

[16] A.M. McDonagh, M.P. Cifuentes, M.G. Humphrey, S. Houbrechts, J. Maes, A. Persoons, M. Samoc, B. Luther-Davies, J. Organomet. Chem. 610 (2000) 71.

[17] F. Paul, K. Costuas, I. Ledoux, S. Deveau, J. Zyss, J.F. Halet, C. Lapinte, Organometallics 21 (2002) 5229.

[18] M.H. Garcia, M.P. Robalo, A.R. Dias, M.T. Duarte, W. Wenseleers, G. Aerts, E. Goovaerts, M.P. Cifuentes, S. Hurst, M.G. Humphrey, M. Samoc, B. Luther-Davies, Organometallics 21 (2002) 2107.

[19] S.K. Hurst, M.P. Cifuentes, J.P. Morrall, N.T. Lucas, I.R. Whittall, M.G. Humphrey, I. Asselberghs, A. Persoons, M. Samoc, B. Luther-Davies, A.C. Willis, Organometallics 20 (2001) 4664.

[20] I.R. Whittall, M.G. Humphrey, A. Persoons, S. Houbrechts, Organometallics 15 (1996) 1935. 
[21] B. Babgi, A. Al-Hindawi, G.J. Moxey, F.I. Abdul Razak, M.P. Cifuentes, E. Kulasekera, R. Stranger, A. Teshome, I. Asselberghs, K. Clays, M.G. Humphrey, J. Organomet. Chem. 730 (2013) 108.

[22] See, for instance: K. Costuas, S. Rigaut, Dalton Trans. 40 (2011) 5643.

[23] R.H. Naulty, A.M. McDonagh, I.R. Whittall, M.P. Cifuentes, M.G. Humphrey, S. Houbrechts, J. Maes, A. Persoons, G.A. Heath, D.C.R. Hockless, J. Organomet. Chem. 563 (1998) 137.

[24] A.M. McDonagh, N.T. Lucas, M.P. Cifuentes, M.G. Humphrey, S. Houbrechts, A. Persoons, J. Organomet. Chem. 605 (2000) 193.

[25] J. Vicente, M.-T. Chicote, M.D. Abrisqueta, M.C. Ramîrez de Arellano, P.G. Jones, M.G. Humphrey, M.P. Cifuentes, M. Samoc, B. Luther-Davies, Organometallics 19 (2000) 2968.

[26] A.M. McDonagh, M.P. Cifuentes, I.R. Whittall, M.G. Humphrey, M. Samoc, B. LutherDavies, D.C.R. Hockless, J. Organomet. Chem. 526 (1996) 99.

[27] S.K. Hurst, M.G. Humphrey, J.P. Morrall, M.P. Cifuentes, M. Samoc, B. Luther-Davies, G.A. Heath, A.C. Willis, J. Organomet. Chem. 670 (2003) 56.

[28] B. Babgi, L. Rigamonti, M.P. Cifuentes, T.C. Corkery, M.D. Randles, T. Schwich, S. Petrie, R. Stranger, A. Teshome, I. Asselberghs, K. Clays, M. Samoc, M.G. Humphrey, J. Am. Chem. Soc. 131 (2009) 10293.

[29] N. Gauthier, PhD Thesis, Université Rennes 1, France, 2008.

[30] I.R. Whittall, M.P. Cifuentes, M.G. Humphrey, B. Luther-Davies, M. Samoc, S. Houbrechts, A. Persoons, G.A. Heath, D.C.R. Hockless, J. Organomet. Chem. 549 (1997) 127.

[31] T.N. Fondum, K.A. Green, M.D. Randles, M.P. Cifuentes, A.C. Willis, A. Teshome, I. Asselberghs, K. Clays, M.G. Humphrey, J. Organomet. Chem. 693 (2008) 1605. 
[32] J.P.L. Morrall, M.P. Cifuentes, M.G. Humphrey, R. Kellens, E. Robijns, I. Asselberghs, K. Clays, A. Persoons, M. Samoc, A.C. Willis, Inorg. Chim. Acta, 359 (2006) 998.

[33] L. Rigamonti, B. Babgi, M.P. Cifuentes, R.L. Roberts, S. Petrie, R. Stranger, S. Righetto, A. Teshome, I. Asselberghs, K. Clays, M.G. Humphrey, Inorg. Chem. 48 (2009) 3562.

[34] M.P. Cifuentes, C.E. Powell, J.P. Morrall, A.M. McDonagh, N.T. Lucas, M.G. Humphrey, M. Samoc, S. Houbrechts, I. Asselberghs, K. Clays, A. Persoons, T. Isoshima, J. Am. Chem. Soc. 128 (2006) 10819.

[35] K.A. Green, M.P. Cifuentes, M. Samoc, M.G. Humphrey, Coord. Chem. Rev. 255 (2011) 2025.

[36] A. Trujillo, R. Veillard, G. Argouarch, T. Roisnel, A. Singh, I. Ledoux, F. Paul, Dalton Trans. 41 (2012) 7454.

[37] Q.Y. Hu, W.X. Lu, H.D. Tang, H.H.Y. Sung, T.B. Wen, I.D. Williams, G.K.L. Wong, Z. Lin, G. Jia, Organometallics 24 (2005) 3966.

[38] O. Maury, H. Le Bozec, Acc. Chem. Res. 38 (2005) 691.

[39] C.J. Adams, L.E. Bowen, M.G. Humphrey, J.P.L. Morrall, M. Samoc, L.J. Yellowlees, Dalton Trans. (2004) 4130.

[40] Q. Ge, T.C. Corkery, M.G. Humphrey, M. Samoc, T.S.A. Hor, Dalton Trans. (2009) 6192.

[41] J. Luc, G. Boudebs, C. Cassagne, J.-L. Fillaut, A. Meghea, I. Rau, A. Migalska-Zalas, M. Bakasse, B. Sahraoui, Nonlinear Opt. Quant. Opt. 38 (2008) 163.

[42] J.-L. Fillaut, J. Perruchon, P. Blanchard, J. Roncali, S. Golhen, M. Allain, A. MigalsakaZalas, I.V. Kityk, B. Sahraoui, Organometallics 24 (2005) 687.

[43] J. Luc, A. Migalska-Zalas, S. Tkaczk, J.F. Andries, J.-L. Fillaut, A. Meghea, B. Sahraoui, J. Optoelectron. Adv. Mater. 10 (2008) 29. 
[44] Q. Ge, G.T. Dalton, M.G. Humphrey, M. Samoc, T.S.A. Hor, Chem. Asian J. 4 (2009) 998.

[45] S. Drouet, A. Mehri, D. Yao, M.P. Cifuentes, M.G. Humphrey, M. Wielgus, J. OlesiakBanska, K. Matczyszyn, M. Samoc, F. Paul, C. Paul-Roth, Tetrahedron 68 (2012) 10351.

[46] S. Drouet, A. Mehri, G. Grelaud, M.P. Cifuentes, M.G. Humphrey, K. Matczyszyn, M. Samoc, L. Toupet, C. Paul-Roth, F. Paul, New J. Chem. 36 (2012) 2192.

[47] G.T. Dalton, M.P. Cifuentes, L.A. Watson, S. Petrie, R. Stranger, M. Samoc, M.G. Humphrey, Inorg. Chem. 48 (2009) 6534.

[48] C.E. Powell, S.K. Hurst, J.P. Morrall, R.L. Roberts, M.P. Cifuentes, M. Samoc, M.G. Humphrey, Organometallics 26 (2007) 4456.

[49] C.E. Powell, J.P. Morrall, S.A. Ward, M.P. Cifuentes, E.G.A. Notaras, M. Samoc, M.G. Humphrey, J. Am. Chem. Soc. 126 (2004) 12234.

[50] C.E. Powell, M.P. Cifuentes, M.G. Humphrey, A.C. Willis, J.P. Morrall, M. Samoc, Polyhedron 26 (2007) 284.

[51] M. Samoc, J.P. Morrall, G.T. Dalton, M.P. Cifuentes, M.G. Humphrey, Angew. Chem. Int. Ed. 46 (2007) 731.

[52] M. Samoc, T.C. Corkery, A.M. McDonagh, M.P. Cifuentes, M.G. Humphrey, Aust. J. Chem. 64 (2011) 1269.

[53] R.L. Roberts, T. Schwich, T.C. Corkery, M.P. Cifuentes, K.A. Green, J.D. Farmer, P.J. Low, T.B. Marder, M. Samoc, M.G. Humphrey, Adv. Mater. 21 (2009) 2318.

[54] J.G. Perez-Moreno, M.G. Kuzyk, Adv. Mater. 23 (2011) 1428.

[55] T. Schwich, M.P. Cifuentes, P.A. Gugger, M. Samoc, M.G. Humphrey, Adv. Mater. 23 (2011) 1433. 
[56] S.K. Hurst, M.G. Humphrey, T. Isoshima, K. Wostyn, I. Asselberghs, K. Clays, A. Persoons, M. Samoc, B. Luther-Davies, Organometallics 21 (2002) 2024.

[57] S.K. Hurst, N.T. Lucas, M.G. Humphrey, T. Isoshima, K. Wostyn, I. Asselberghs, K. Clays, A. Persoons, M. Samoc, B. Luther-Davies, Inorg. Chim. Acta 350 (2003) 62.

[58] C.J. Jeffery, M.P. Cifuentes, A.C. Willis, M. Samoc, M.G. Humphrey, Macromol. Rapid Commun. 31 (2010) 846.

[59] K.A. Green, T.C. Corkery, P.V. Simpson, M.P. Cifuentes, M. Samoc, M.G. Humphrey, Macromol. Rapid Commun. 33 (2012) 573.

[60] B.J. Coe, Acc. Chem. Res. 39 (2006) 383.

[61] I. Asselberghs, K. Clays, A. Persoons, M.D. Ward, J. McCleverty, J. Mater. Chem. 14 (2004) 2831.

[62] B.J. Coe, Chem. Eur. J. 5 (1999) 2464.

[63] T. Weyland, I. Ledoux, S. Brasselet, J. Zyss, C. Lapinte, Organometallics 19 (2000) 5235.

[64] M.P. Cifuentes, C.E. Powell, M.G. Humphrey, G.A. Heath, M. Samoc, B. LutherDavies, J. Phys. Chem. A 105 (2001) 9625.

[65] C.E. Powell, M.P. Cifuentes, J.P.L. Morrall, R. Stranger, M.G. Humphrey, M. Samoc, B. Luther-Davies, G.A. Heath, J. Am. Chem. Soc. 125 (2003) 602.

[66] C.E. Powell, M.G. Humphrey, M.P. Cifuentes, J.P. Morrall, M. Samoc and B. LutherDavies, J. Phys. Chem. A 107 (2003) 11264.

[67] M.P. Cifuentes, M.G. Humphrey, J.P. Morrall, M. Samoc, F. Paul, C. Lapinte, T. Roisnel, Organometallics 24 (2005) 4280.

[68] N. Gauthier, G. Argouarch, F. Paul, A.K. Ladjarafi, K. Costuas, J.-F. Halet, M. Samoc, M.P. Cifuentes, T.C. Corkery, M.G. Humphrey, Chem.-Eur. J. 17 (2011) 5561. 
[69] G.T. Dalton, M.P. Cifuentes, S. Petrie, R. Stranger, M.G. Humphrey, M. Samoc, J. Am. Chem. Soc. 129 (2007) 11882.

[70] K.A. Green, M.P. Cifuentes, T.C. Corkery, M. Samoc, M.G. Humphrey, Angew. Chem. Int. Ed. 48 (2009) 7867.

[71] http://www.pcinpact.com/actu/news/42473-IBM-switch-nanophotonique.htm?vc=1. Accessed on 26 September, 2013.

[72] J.I. Dadap, N.C. Panoiu, X. Chen, W. Hsieh, X. Liu, C.-Y. Chou, E. Dulkeith, S.J. McNab, F. Xia, W.M.J. Green, L. Sekaric, Y.A. Vlasov, R.M. Osgood, Jr. Optics Express 16 (2008) 1280.

[73] T. Kondo, S. Horiuchi, I. Yagi, S. Ye, K. Uosaki, J. Am. Chem. Soc. 121 (1999) 391.

[74] L. Boubekeur-Lecaque, B.J. Coe, K. Clays, S. Foerier, T. Verbiest, I. Asselberghs, J. Am. Chem. Soc. 130 (2008) 3286.

[75] A. Migalska-Zalas, Z. Sofiani, B. Sahraoui, I.V. Kityk, S. Tkaczyk, V. Yuvshenko, J.L. Fillaut, J. Perruchon, T.J.J. Muller, J. Phys. Chem. B 108 (2004) 14942.

[76] A. Migalska-Zalas, B. Sahraoui, I.V. Kityk, S. Tkaczyk, V. Yuvshenko, J.-L. Fillaut, J. Perruchon, T.J.J. Muller, Phys. Rev. B 71 (2005) 035119.

[77] J. Luc, J. Niziol, M. Sniechowski, J.-L. Fillaut, B. Sahraoui, O. Krupka, Mol. Cryst. Liq. Cryst. 485 (2008) 990,

[78] B. Sahraoui, J. Luc, A. Meghea, R. Czaplicki, J.-L. Fillaut, A. Migalska-Zalas, J. Opt. A $11(2009) 024005$.

[79] M. Makowska-Janusik, I.V. Kityk, N. Gauthier, F. Paul, J. Phys. Chem. C 111 (2007) 12094.

[80] L.R. Dalton, P.A. Sullivan, D.H. Bale, Chem. Rev. 110 (2010) 25.

[81] C. D’Amico, M. Lorenc, E. Collet, K.A. Green, K. Costuas, O. Mongin, M. BlanchardDesce, F. Paul, J. Phys. Chem. C 116 (2012) 3719. 
[82] S. Takahashi, H. Morimoto, E. Murata, S. Kataoka, S. Sonogashira, N. Hagihara, J. Polym. Sci. 20 (1982) 565, and references therein.

[83] C.C. Frazier, S. Guha, W.P. Chen, M.P. Cockerham, P.L. Porter, E. Chauchard, Polymer 28 (1987) 553.

[84] N.J. Long, Angew. Chem., Int. Ed. Engl. 34 (1995) 21.

[85] I.R. Whittall, A.M. McDonagh, M.G. Humphrey, M. Samoc, Adv. Organomet. Chem. 43 (1999) 349.

[86] P.N. Prasad, D.J. Williams, Introduction to Nonlinear Optical Effects in Molecules and Polymers; John Wiley \& Sons: New York, 1991.

[87] J. Luc, J.-L. Fillaut, J. Niziol, B. Sahraoui, J. Optoelectronics Adv. Mater. 9 (2007) 2826.

[88] J. Luc, J. Niziol, M. Sniechowski, J.-L. Fillaut, B. Sahraoui, O. Krupka, Mol. Cryst. Liq. Cryst. 485 (2008) 990.

[89] K.N. Gherab, R. Gatri, J.-L. Fillaut, J. Luc, B. Sahraoui, J. Nicol, Nonlinear Opt. Quant. Opt. 32 (2008) 281.

[90] F. Kajzar, J. Messier, C. Rosilio, J. Appl. Phys. 60 (1986) 3040.

[91] R. Gatri, J.-L. Fillaut, J. Mysliwiec, A. Szukalski, S. Bartkiewicz, H. El-Ouazzani, I. Guezguez, F. Khammar, B. Sahraoui, Chem. Phys. Lett. 535 (2012) 106.

[92] J. Niziol, J.-L. Fillaut, M. Sniechowski, F. Khammar, B. Sahraoui, Opt. Mater. 34 (2012) 1670.

[93] J. Luc, K. Bouchouit, R. Czaplicki, J.-L. Fillaut, B. Sahraoui, Optics Express 16 (2008) 15633.

[94] B. Sahraoui, J. Luc, A. Meghea, R. Czaplicki, J.-L. Fillaut, A. Migalska-Zalas, J. Opt. A 11 (2009) 024005. 
[95] K.N. Gherab, R. Gatri, J.-L. Fillaut, J. Luc, B. Sahraoui, J. Niziol, Nonlinear Opt. Quant. Opt. 32 (2009) 281.

[96] K.N. Gherab, R. Gatri, Z. Hank, B. Dick, R.-J. Kutta, R. Winter, J. Luc, B. Sahraoui, J.L. Fillaut, J. Mater. Chem. 20 (2010) 2858.

[97] N. Gauthier, G. Argouarch, F. Paul, M.G. Humphrey, L. Toupet, S. Ababou-Girard, H. Sabbah, P. Hapiot, B. Fabre, Adv. Mater. 20 (2008) 1952.

[98] K.A. Green, N. Gauthier, H. Sahnoune, J.-F. Halet, F. Paul, B. Fabre, Organometallics 32 (2013) 4366.

[99] L. Boubekeur-Lecaque, B. J. Coe, K. Clays, S. Foerier, T. Verbiest, I. Asselberghs, J. Am. Chem. Soc. 130 (2008) 3286.

[100] G. Grelaud, B. Fabre, F. Paul, M. G. Humphrey, unpublished results. 